Contract No. and Disclaimer:

This manuscript has been authored by Savannah River Nuclear Solutions, LLC under Contract No. DE-AC09-08SR22470 with the U.S. Department of Energy. The United States Government retains and the publisher, by accepting this article for publication, acknowledges that the United States Government retains a non-exclusive, paid-up, irrevocable, worldwide license to publish or reproduce the published form of this work, or allow others to do so, for United States Government purposes. 


\title{
Post-Operational Treatment of Residual Na Coolant in EBR-II Using Carbonation
}

\author{
Steven R. Sherman ${ }^{1}$ and Collin J. Knight ${ }^{2}$ \\ 'Savannah River National Laboratory \\ 2Idaho National Laboratory
}

USA

\section{Introduction}

The Experimental Breeder Reactor Two (EBR-II) was an unmoderated, heterogeneous, sodium-cooled fast breeder reactor operated by Argonne National Laboratory - West, now part of the Idaho National Laboratory in southeastern Idaho, USA. It was a pool-type reactor. The reactor core, sodium fluid pumps, and intermediate heat exchanger (IHX) were submerged in a tank of molten sodium, and the exchange of heat from the core was accomplished by pumping molten sodium from the pool through the reactor core, IHX, then back into the pool. Thermal energy from the pool was transmitted in the IHX to a secondary sodium loop, which in turn was used to heat high-pressure steam for electricity production. When it operated, the nominal power output of the reactor was 62.5 MW thermal and approximately $20 \mathrm{MW}$ electrical. The reactor began operation in 1964 and operated until final reactor shutdown in 1994. During its lifetime, the reactor served as a test facility for fuels development, hardware validation, materials irradiation, and system and control theory testing.

From 1994 through 2002, the reactor was de-fueled, systems not essential to reactor or facility safety were deactivated or removed, and the primary and secondary sodium systems were drained of sodium metal. During operation, the sodium pool contained approximately $3.4 \times 10^{5}$ liters of molten sodium, and the secondary sodium system contained $4.9 \times 10^{4}$ liters. After draining these systems, some sodium metal remained behind in hydraulic low spots and as a coating on exposed surfaces. It is estimated that the EBR-II primary tank contained approximately 1100 liters, and the EBR-II secondary sodium system retained approximately 400 liters of sodium metal after being drained. The sodium metal remaining in these systems after the coolant was drained is referred to as residual sodium.

At the end of 2002, the EBR-II facility became a U.S. Resource Conservation and Recovery Act (RCRA) permitted site, and the RCRA permit ${ }^{1}$ compelled further treatment of the residual sodium in order to convert it into a less reactive chemical form and remove the byproducts from the facility, so that a state of RCRA "closure" for the facility may be achieved (42 U.S.C. 6901-6992k, 2002).

\footnotetext{
${ }^{1}$ Hazardous Waste Management Act (HWMA)/ RCRA Partial Permit, EBR-II, EPA ID No. ID489000892, effective December 10, 2002 (Part B).
} 
In response to this regulatory driver, and in recognition of project budgetary and safety constraints, it was decided to treat the residual sodium in the EBR-II primary and secondary sodium systems using a process known as "carbonation." In early EBR-II post-operation documentation, this process is also called "passivation." In the carbonation process (Sherman and Henslee, 2005), the system containing residual sodium is flushed with humidified carbon dioxide $\left(\mathrm{CO}_{2}\right)$. The water vapor in the flush gas reacts with residual sodium to form sodium hydroxide $(\mathrm{NaOH})$, and the $\mathrm{CO}_{2}$ in the flush gas reacts with the newly formed $\mathrm{NaOH}$ to make sodium bicarbonate $\left(\mathrm{NaHCO}_{3}\right)$. Hydrogen gas $\left(\mathrm{H}_{2}\right)$ is produced as a by-product. The chemical reactions occur at the exposed surface of the residual sodium. The $\mathrm{NaHCO}_{3}$ layer that forms is porous, and humidified carbon dioxide can penetrate the $\mathrm{NaHCO}_{3}$ layer to continue reacting residual sodium underneath. The rate of reaction is controlled by the thickness of the $\mathrm{NaHCO}_{3}$ surface layer, the moisture input rate, and the residual sodium exposed surface area.

At the end of carbonation, approximately 780 liters of residual sodium in the EBR-II primary tank ( $70 \%$ of original inventory), and just under 190 liters of residual sodium in the EBR-II secondary sodium system ( $\sim 50 \%$ of original inventory), were converted into $\mathrm{NaHCO}_{3}$. No bare surfaces of residual sodium remained after treatment, and all remaining residual sodium deposits are covered by a layer of $\mathrm{NaHCO}_{3}$. From a safety standpoint, the inventory of residual sodium in these systems was greatly reduced by using the carbonation process. From a regulatory standpoint, the process was not able to achieve deactivation of all residual sodium, and other more aggressive measures will be needed if the remaining residual sodium must also be deactivated to meet the requirements of the existing environmental permit.

This chapter provides a project history and technical summary of the carbonation of EBR-II residual sodium. Options for future treatment are also discussed.

The information collected during the EBR-II post-treatment operation provides guideposts for engineers who must design future sodium-cooled reactors, or who are tasked with cleaning up shutdown sodium-cooled reactor systems. The single, most important lesson to be imparted to the designers of new sodium-cooled reactor systems is this: design systems so that they can be drained effectively at all points, and avoid the creation of hydraulic low spots and "dead ends" that are inaccessible. Observation of this lesson in future designs will minimize the number and size of residual sodium pockets upon drainage of the sodium coolant and increase the effectiveness of any clean-up method, including carbonation. In addition, post-operation cleanup of new sodium-cooled reactor systems will be safer, faster, and less costly.

Lessons may also be drawn from this work for those who wish to react or remove residual sodium from non-nuclear systems such as coolant pipelines, tanks, and drums. The carbonation method is generally applicable to such systems, and is not specific to nuclear reactors.

\section{Residual sodium inventory determination}

The EBR-II Primary Sodium System consisted of components in the EBR-II Primary Tank and supporting systems that came in contact with the primary sodium coolant (i.e., argon cover gas clean-up system, sodium vapor traps). Figure 1 shows a schematic of the EBR-II Primary Tank, which includes the reactor core. The black arrows in Figure 1 show the flow path for sodium coolant from the pool through the reactor core and back to the pool. A detailed description of EBR-II systems and components may be found in Koch, 2008. 


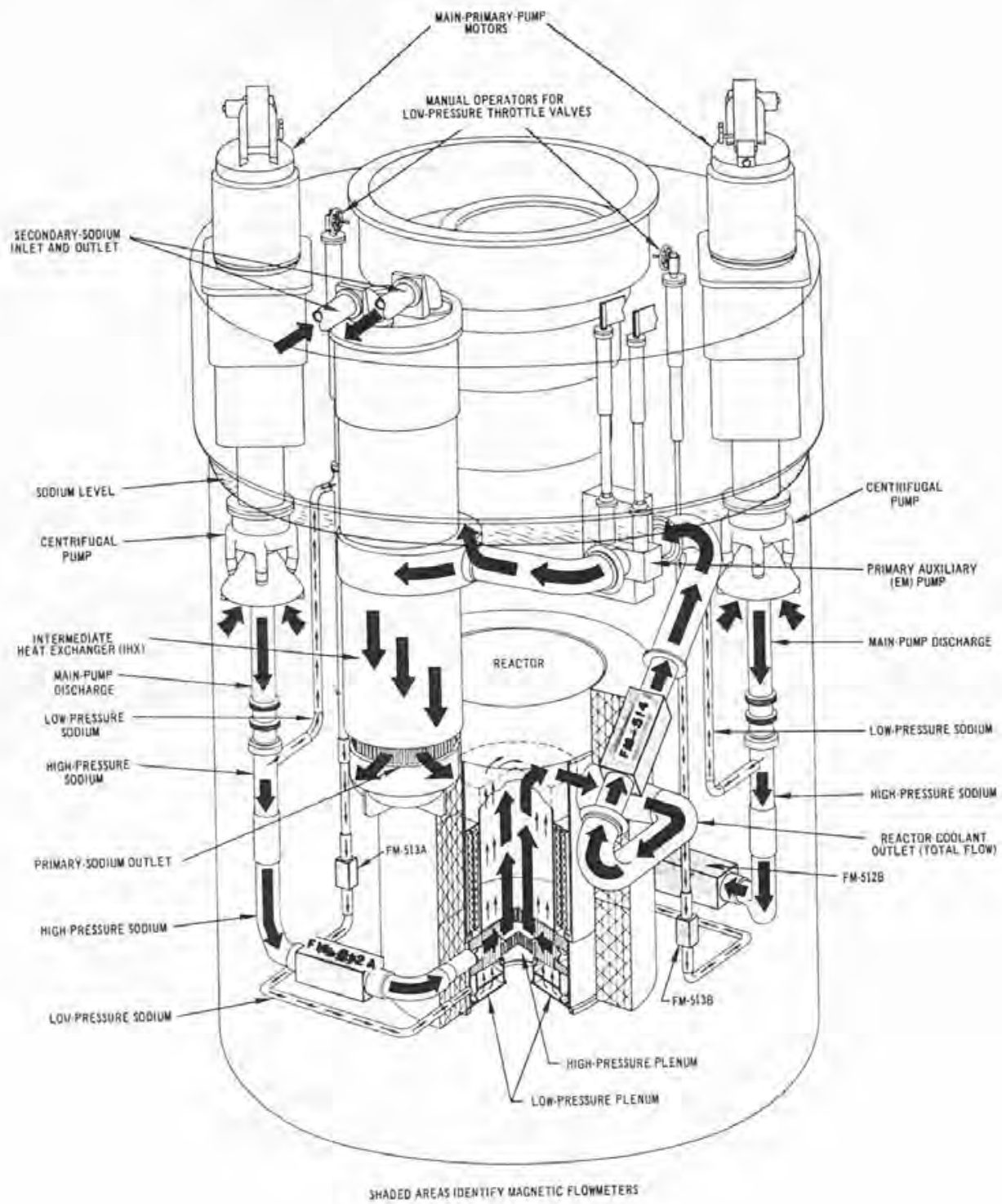

Fig. 1. Schematic of EBR-II Primary Tank and internal systems.

The EBR-II Secondary Sodium System consisted of a network of pipes, steam evaporators, and steam superheaters. In the Secondary Sodium System, molten sodium metal circulated through the IHX in the Primary Tank in order to remove thermal energy from the sodium pool, and then returned to the Secondary Sodium System, where it provided heat to make superheated steam. The system was a closed loop, and sodium metal exiting the Secondary Sodium System was recycled to the IHX. 
After shutdown and drainage of the bulk sodium coolant, the Secondary Sodium System delivery/return pipeline was severed from the IHX, and the Secondary Sodium System piping network was re-routed to provide common input and output locations for residual sodium treatment gases. Schematics showing the EBR-II Secondary Sodium System configuration during regular operation and after reactor shutdown are shown in Figures 2 and 3.
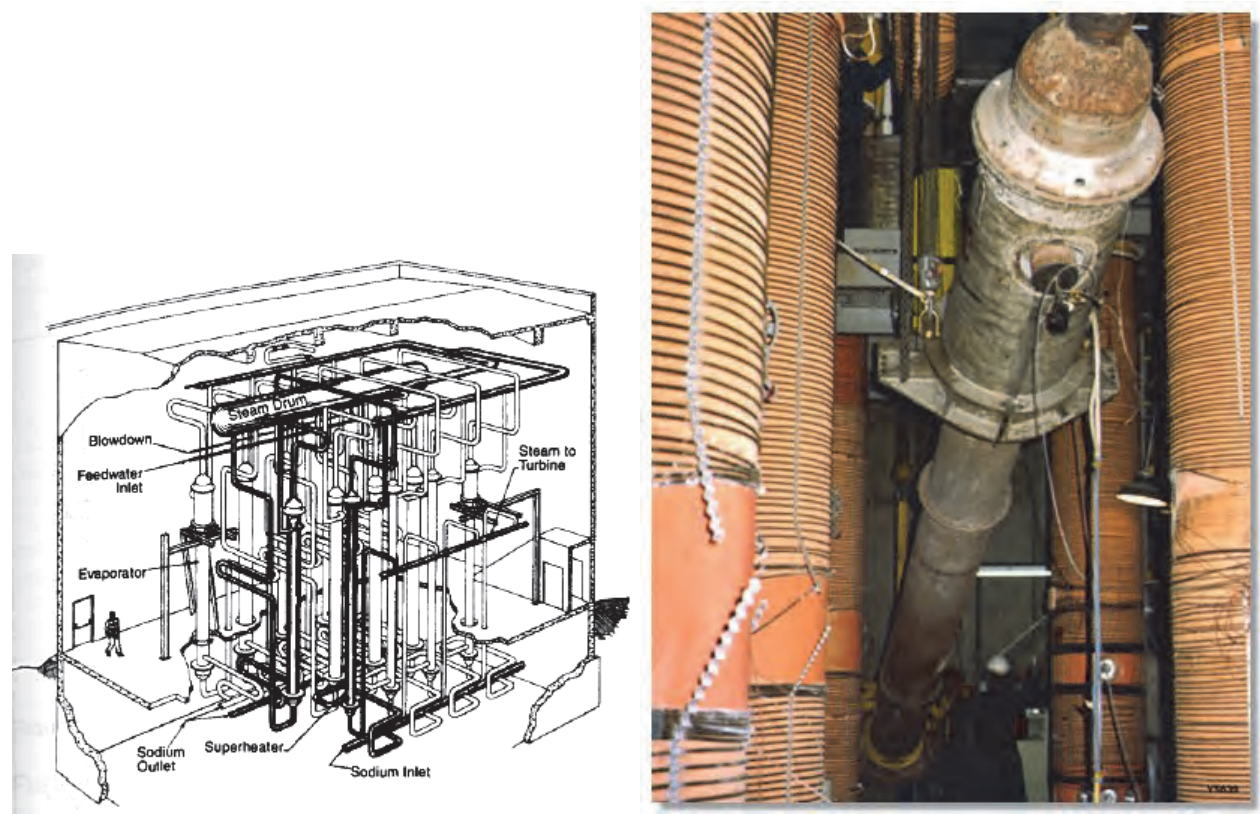

Fig. 2. Schematic and photo of EBR-II Secondary Sodium System as it was configured during regular operations

Determination of the sodium metal inventory during regular operation was relatively easy and straightforward. Operational records were available that provided the amount of sodium metal added to each system before initial reactor start-up. Measurements of the liquid level in the EBR-II Primary Tank and other systems could be tied to these operational records, and the losses of any sodium metal due to the removal of sodium-wetted or sodium-filled components, evaporation of sodium vapor from the pool, and other events, could be correlated to changes in the measured sodium liquid level. All system components were immersed in sodium, and the geometry and configuration of the submerged components had no effect on the determination of the bulk sodium inventory.

After the bulk sodium was drained from these systems, direct observation and measurement of the residual sodium inventory was no longer possible. Residual sodium is not a single entity, and is a collection of localized sodium deposits of heterogeneous depth and physical configuration. The amount of residual sodium at any particular location is highly dependent upon the geometry, elevation, orientation, and configuration of that location. Only a limited number of suspected locations of residual sodium could be visually inspected due to physical access limitations or the presence of radioactive contamination or high radiation fields, and direct measurement of the residual sodium inventory could not be performed. 


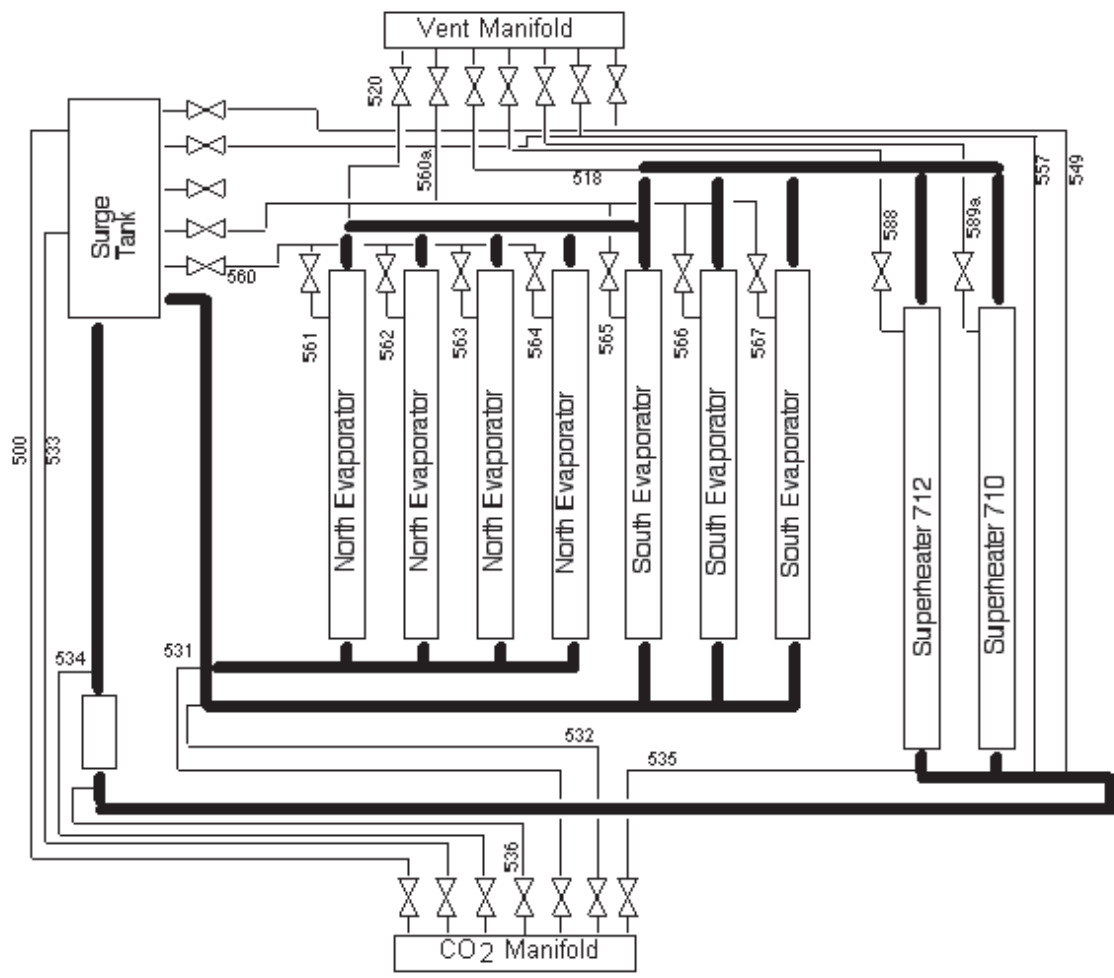

Fig. 3. Schematic of the EBR-II Secondary Sodium System as it was configured during postoperation residual sodium treatment.

An initial estimate of the total residual sodium inventory in these systems was calculated by taking the difference between the known volume of sodium coolant that was present during regular operation, and the amount of sodium collected upon draining the systems. The amount drained from each system, however, was very nearly equal to the known amount of sodium in each system, and only an imprecise determination of residual sodium amounts could be made due to rounding error. By this method, the amount of residual sodium in the Primary Tank and Secondary Sodium System was estimated to be greater than zero and less than 4000 liters and 1000 liters, respectively.

Since fulfillment of the RCRA environmental permit requires that all residual sodium be deactivated or removed, a more precise determination of the starting amount of residual sodium was needed. Assuming a residual treatment process of any kind is monitored and controlled, it should be possible to assess how much sodium has been deactivated or removed at any point in time during the treatment process. This does not, however, provide any measure of how long a treatment process must be performed to reach an end point. For example, if it is known that 500 liters of residual sodium has been deactivated at a certain point in time, what fraction of the total inventory of residual sodium does this represent? Is this $20 \%$ of the inventory, or is it $80 \%$ of the inventory? Without a more precise point estimate of the initial residual sodium inventory, progress towards an end point can't be 
assessed, and the treatment process must be carried out indefinitely until some measured output of the treatment process indicates that a physical end point has been reached.

At worst case, it could have been assumed that the inventory of residual sodium in each system is equal to the upper bound (4000 liters of residual sodium in the Primary Tank and 1000 liters in the Secondary Sodium System), but this likely would have established a treatment target that could never be reached. For example, if the actual residual sodium inventory in the Primary Tank were 2000 liters, and a residual sodium treatment process were applied to it, then the treatment process could potentially be carried out until all 2000 liters of residual sodium were consumed. This would be an excellent result, but the treatment target was established at 4000 liters, and the treatment process would therefore be assessed as being only $50 \%$ complete. One could then try to argue with the regulator that the wrong target was chosen and system treatment is complete, but it would be difficult to verify whether this was indeed the case without direct inspection, or whether the treatment method had stopped working for some other reason, and more residual sodium lies within awaiting further treatment.

There is less project risk if the chosen treatment target is less than the actual residual sodium inventory. In this case, achieving less than $100 \%$ deactivation of residual sodium is sufficient to achieve project "success", but success would be illusory. Physical evidence from the treatment process would likely indicate that more residual sodium remained in the system being treated after achievement of the project target, and the treatment process would need to be continued anyway until a true endpoint was reached. Extension of the treatment process past the treatment target might then result in increased project costs and schedule delays if the additional treatment work was not planned. Continuing the treatment process past a previously agreed upon target value, however, is more easily acceptable to a regulator, because it would show that the project team was willing to go "above and beyond" the original work scope to achieve environmental goals, and that would reflect more favorably on the clean-up project.

So, there is incentive to choose treatment targets that are less than the upper bounds discussed above, but selection of these targets cannot be done arbitrarily. Project sponsors do not like cost overruns and schedule delays, and will demand a residual sodium inventory estimate that is based on observable data, or that is supported by well-reasoned arguments.

For the EBR-II systems, a mathematical approach was developed for calculating probable residual sodium quantities. The engineering drawings for each system and subsystem were examined, and hydraulic low points were identified. The volume of residual sodium that could be contained in each hydraulic low points was calculated based on the geometry of the location and the presence or absence of drainage points, and the individual volumes were added to calculate the total residual sodium inventory in each system. As a result of this method, the Primary Tank was calculated to contain approximately 1120 liters of residual sodium, and the Secondary Sodium System was determined to contain approximately 400 liters. The detailed calculations are described below.

\subsection{EBR-II primary tank residual sodium volume determination}

Twenty-four locations were judged likely to contain residual sodium within the Primary Tank. These locations are hydraulic low points, or places where sodium metal may have collected during regular operations but would have failed to drain when the Primary Tank 
was emptied. The physical dimensions of each location were then determined from the engineering drawings, and the amount of residual sodium that could have been retained at each location was calculated. The calculated amounts of residual sodium at these locations are shown in Table 1.

For horizontal locations facing upward against gravity, the residual sodium at each location was assumed to have drained to the lowest possible point of drainage, and no blocked drainage points were assumed.

\begin{tabular}{|c|c|c|c|}
\hline Location & Name & $\begin{array}{c}\text { Deposit Volume } \\
(\mathrm{L})\end{array}$ & $\begin{array}{c}\text { Access } \\
\text { Limitations? }\end{array}$ \\
\hline 1 & Low pressure plenum & 27 & No \\
\hline 2 & High pressure plenum & 125 & Yes \\
\hline 3 & Inlet pipes to high pressure plenum & 117 & Yes \\
\hline 4 & $\begin{array}{l}\text { High pressure plenum inside flow } \\
\text { distributing ring }\end{array}$ & 42 & No \\
\hline 5 & $\begin{array}{l}\text { Between blanket lower adapter, sleeve } \\
\text { between grid plates }\end{array}$ & 0 & Yes \\
\hline 6 & Control rod position dummy assembly & 0 & Yes \\
\hline 7 & $\begin{array}{l}\text { Inner shield area between inner and outer } \\
\text { walls and outlet }\end{array}$ & 11 & No \\
\hline 8 & $\begin{array}{l}\text { Inner shield region between thermal baffle } \\
\text { and outer wall }\end{array}$ & 11 & Yes \\
\hline 9 & Top flange of reactor vessel & 15 & Yes \\
\hline 10 & Reactor cover thermal baffles & 11 & Yes \\
\hline 11 & $\begin{array}{l}\text { Sleeves \& bellows for gripper, aux. gripper } \\
\text { and hold down }\end{array}$ & 11 & Yes \\
\hline 12 & Sleeves and bellows for control rod drives & 8 & Yes \\
\hline 13 & Guide funnels for control rod drives & 38 & Yes \\
\hline 14 & $\begin{array}{l}\text { Outside flow baffle around gripper/hold } \\
\text { down }\end{array}$ & 11 & Yes \\
\hline 15 & $\begin{array}{l}\text { Inside flow baffle around gripper/hold } \\
\text { down }\end{array}$ & 0 & No \\
\hline 16 & Recessed area around lifting columns & 8 & No \\
\hline 17 & Safety rod drive lift tubes & 1 & Yes \\
\hline 18 & Transfer arm pedestal & 4 & Yes \\
\hline 19 & Pressure transmitting piping & 8 & Yes \\
\hline 20 & Heater guide funnels & 2 & Yes \\
\hline 21 & Auxiliary pump bellows & 2 & No \\
\hline 22 & Pipe supports & 0 & No \\
\hline 23 & Primary tank bottom & 473 & No \\
\hline 24 & Bottom of Primary Tank cover & 189 & No \\
\hline & Sub-total, access limitations & 364 & \\
\hline & Sub-total, no access limitations & 752 & \\
\hline \multicolumn{2}{|r|}{ Total } & 1116 & \\
\hline
\end{tabular}

Table 1. Residual sodium locations in the EBR-II Primary Tank. 
For vertical surfaces such as the side walls of the Primary Tank, no significant deposits of residual sodium were assumed. This assumption was verified by a video examination of the Primary Tank interior which showed no adhering residual sodium on the side walls of the Primary Tank after the bulk sodium had been drained.

Downward facing horizontal surfaces were generally assumed to be residual sodium-free with the exception of the Primary Tank Cover. The bottom surface of the Primary Tank Cover has a complex geometry, and there were many places for residual sodium to be retained. Also, it was known from regular operating experience that the penetrations in the Primary Tank Cover were slightly cooler than the Primary Tank side walls and submerged components, and residual sodium tended to accumulate at certain locations under the cover due to condensation of sodium vapor and the capture of sodium aerosol.

The largest deposit of residual sodium was on the bottom of the Primary Tank. The depth of residual sodium at this location was determined by calculating the gap space $(0.95 \mathrm{~cm})$ between the tank bottom and the bottom of the pump suction that was used to withdraw bulk sodium from the tank. Assuming the Primary Tank bottom is perfectly flat, the volume of residual sodium was calculated by assuming a circular area with a diameter equal to the inner diameter of the Primary Tank minus the projected areas of structures attached to the Primary Tank floor. The Primary Tank had no drain hole, so no further sodium could be drained beyond the lower reach of the pump.

The second largest location for residual sodium is on the bottom of the Primary Tank Cover. No accurate mathematical estimate of residual sodium in this location could be determined, so a guess of 50 gallons (189 liters) was assumed.

The other residual sodium deposits are located in areas that are hydraulic low spots and that have no known drainage points. These areas also include the narrow gap spaces in architectural features that wouldn't have drained well due to surface tension effects, such as the Reactor Cover Thermal Baffles. A detailed examination of engineering drawings of these areas provided the physical dimensions of prospective residual sodium deposits, and the volume of each residual sodium location could be calculated once the dimensions of the locations were known.

After identifying and quantifying residual sodium locations, the locations were also characterized according to their accessibility to the gas space of the Primary Tank. Locations open to the Primary Tank were judged to be completely accessible to any treatment method, while locations with narrow or limited access to the Primary Tank gas space were judged to be only partially accessible, or inaccessible to all but the most severe treatment methods (i.e., filling the Primary Tank with liquid water).

\subsection{EBR-II secondary sodium system residual sodium volume determination}

An examination of the engineering drawings of the heat exchanger equipment, and a physical examination of the piping network to identify elbows, dead legs, and hydraulic low spots revealed that residual sodium was located throughout the Secondary Sodium System in varying amounts. The largest deposits for residual sodium were identified to reside in the bottom of the steam evaporators and superheaters, and each evaporator and superheater was estimated to contain at least 10 liters of residual sodium. A precise amount of residual sodium could not be determined, but it was estimated that the Secondary Sodium System contained approximately 400 liters of residual sodium based upon these examinations.

Less emphasis was placed on calculating precise residual sodium volumes because the components of the Secondary Sodium System were physically accessible. The progress of 
any residual sodium treatment operation or verification of its completion could be checked by cutting open the component or system being treated and examining the contents. Also, if a component or system could not be treated completely using an in-situ method, the component or system could be cut out and dismantled for further treatment at INL's Sodium Component Maintenance Shop (SCMS), a facility used to clean and repair sodiumcoated components.

\section{Selection of residual sodium treatment method}

The selection of a residual sodium treatment method was motivated by the requirements of the EBR-II RCRA permit, and the need to maintain a safe work environment while performing residual sodium treatment processes. A RCRA closure permit is a goal-driven document that requires that the permit holder achieve "closure" of the affected system or systems within a defined period of time, usually within 10-20 years of permit issue. The RCRA laws define the closure process as direct removal of RCRA-listed hazardous components, or deactivation (i.e., chemical transformation of a hazardous component into a non-hazardous component) of RCRA-listed components followed by removal of the deactivation products. Once the affected system(s) have been cleaned of hazardous components or deactivation products, an examination of the system by a professional engineer is required to verify the end state. After the inspection step, the affected system(s) is classified as RCRA-closed, and the environmental permit is closed out. Partial closure of a complex system may be performed if a larger system can be divided into smaller, isolated sections that can be treated individually. In cases where complete deactivation or removal cannot be achieved, then the law provides a risk-based closure process that allows some amount of hazardous components or deactivation products to remain in place if the remaining inventory does not pose a risk to human health or the environment. The EBR-II RCRA permit was issued and is administered by the State of Idaho Department of Environmental Quality (Idaho DEQ) on behalf of the U.S. Environmental Protection Agency (U.S. EPA).

In the case of the EBR-II Secondary Sodium System, a RCRA-closed state could be achieved by mechanically extracting the components containing residual sodium (e.g., pipes, tanks, vessels), and treating the pieces one-at-a-time in the on-site Sodium Component Maintenance Shop (SCMS). This approach constitutes a "closure by removal" strategy. Although definitive, it was decided that cutting apart the Secondary Sodium System, packaging and shipping the pieces to the on-site treatment facility, and treating the pieces individually would be too costly in regard to available funding. Also, the dismantling work posed an unacceptably high risk of worker exposure to hazardous chemicals and risk of fire. In addition, the residual sodium in the Secondary Sodium System contains a small amount of tritium, and workers would incur a measurable radiation dose during any dismantling operation.

For the EBR-II Primary Tank, a dismantling operation was out of the question due to the presence of a high radiation field and radioactive contamination in the tank. A radiation monitor inserted into the Primary Tank measured a radiation field strength of $50 \mathrm{R} /$ hour just beneath the Primary Tank cover, and higher radiation levels are likely present nearer to the core. Significant sources of radiation in the Primary Tank are Co-60, which is present as fixed contamination in the reactor structural materials, and Na-22, and Cs-137, which are present in the residual sodium. 
In-situ treatment methods were then considered. The application of an in-situ treatment method is a "treat, then remove" strategy. The residual sodium in the affected system(s) is reacted in order to transform it into a non-hazardous material, or a less hazardous material, and then the reaction product(s) are removed from the system. Removal of the reaction product(s) is then performed by draining the system if the reaction product is a liquid, or, if the reaction product is a solid, by flushing the system with a solvent in order to dissolve and remove the solid reaction product.

Three in-situ treatment methods were examined in detail, all of which involve the injection of a reacting gas into the system being treated. These methods are the Steam-Nitrogen Process, the Water Vapor Nitrogen (WVN) Process, and the Carbonation Process. The methods were compared on the basis of safety, cost, and schedule. After considerable study and discussion among treatment project engineers, and between treatment project engineers and a sub-set of the engineers who originally designed and built EBR-II, it was decided to pursue carbonation as an in-situ treatment method. A detailed description of these in-situ treatment method, and the selection process, is found in the sub-sections below.

\subsection{Steam-Nitrogen Process}

In the Steam-Nitrogen Process, steam or superheated steam mixed with nitrogen is injected into the system for the purpose of converting residual sodium into sodium hydroxide $(\mathrm{NaOH})$. Hydrogen is also produced. Nitrogen at a concentration of $20-80 \mathrm{vol} \%$ is added as a diluent to suppress the potential for a hydrogen fire or explosion. The stoichiometry of this treatment process is shown in Equations 1 and 2.

$$
\begin{gathered}
\mathrm{Na}(\mathrm{s})+\mathrm{H}_{2} \mathrm{O}(\mathrm{g}) \grave{a} \mathrm{NaOH}(\mathrm{s})+1 / 2 \mathrm{H}_{2}(\mathrm{~g}) \\
\mathrm{NaOH}(\mathrm{s})+n \mathrm{H}_{2} \mathrm{O}(\mathrm{l}, \mathrm{g}) \grave{a} \mathrm{NaOH}\left(\mathrm{H}_{2} \mathrm{O}\right)_{n}(\mathrm{~s}, \mathrm{l}) \quad n=1,2
\end{gathered}
$$

In Equation 1, sodium metal reacts with steam to form $\mathrm{NaOH}$ and hydrogen. Sodium hydroxide is hygroscopic, and absorbs water to form $\mathrm{NaOH}$ hydrates, as shown in Equation 2. Pure $\mathrm{NaOH}$ melts at $318^{\circ} \mathrm{C}$, but sodium hydroxide hydrates for $\mathrm{n}>2$ are liquid at room temperature. Equation 1 occurs at the exposed residual sodium surface, or at the sodium/ $\mathrm{NaOH}$ interface after a $\mathrm{NaOH}$ surface layer has been established. The treatment rate is generally controlled by the steam feed rate, and rapid treatment of systems (i.e., within hours to days) is possible. Equations 1 and 2 are exothermic, and Equation 1 in particular liberates $-184 \mathrm{~kJ} / \mathrm{mol}$ at standard temperature and pressure. The treatment process is carried out continuously until no hydrogen is generated from the system for a defined period of time (generally greater than 1 hour).

The reaction products, $\mathrm{NaOH}$ and $\mathrm{NaOH}$ hydrates, are water-soluble, and may be removed from the treated system after the treatment process is complete by flushing the system with liquid water. The water effluent is highly basic and requires neutralization before further treatment and disposal.

The application of this method to residual sodium is characterized by steady periods of smooth operation, interspersed by erratic and spasmodic reaction behavior, as indicated by spikes in system temperature. An example of a temperature spike is shown in Figure 4, which shows the behavior of a steam treatment experiment performed at Argonne National Laboratory (Sherman et al, 2002). In the figure, somewhat steady reaction behavior is experienced between 75 and 250 minutes, and then a spike in hydrogen concentration (bottom curve) and temperature (top curve) occurs in the reaction chamber at 250 minutes. 


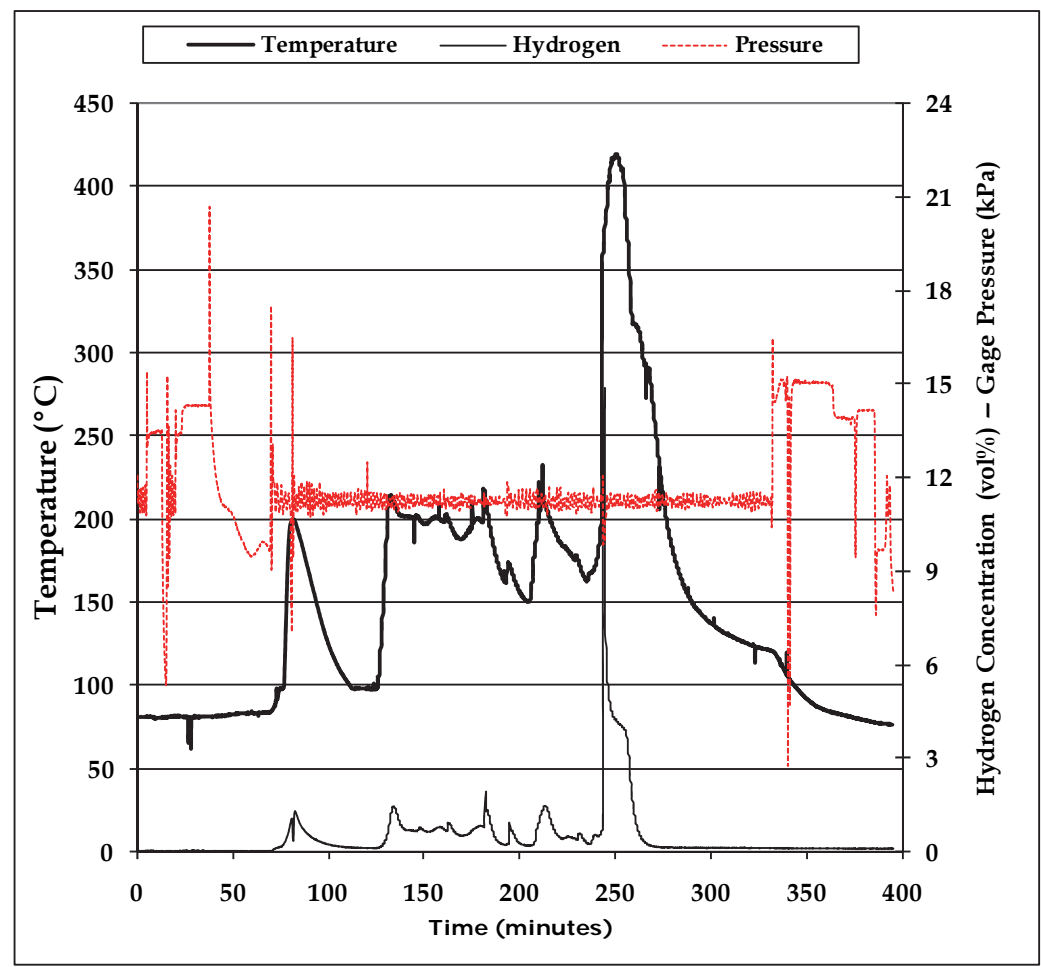

Fig. 4. Measured temperature, guage pressure, and hydrogen concentration in off-gas produced by exposure of sodium metal sample exposed to saturated steam.

Anecdotal evidence seems to indicate that erratic reaction behavior occurs when liquid $\mathrm{NaOH}$ hydrates begin to accumulate. The difference in the melting points of pure $\mathrm{NaOH}$ and its hydrates, and the strong chemical affinity of sodium metal for water, may lead to the formation of a strong water concentration gradient between the residual sodium surface and the free liquid surface. Once a concentration gradient is established, then circulation of hydrogen bubbles through the liquid layer or other physical disruptions may cause convection within the liquid layer, bringing water-enriched $\mathrm{NaOH}$ hydrates in contact with residual sodium, thus causing a sudden acceleration in reaction rate. If the residual sodium temperature is above the melting point of sodium, $97^{\circ} \mathrm{C}$, then droplets of liquid sodium, which are less dense, may rise and contact water-enriched $\mathrm{NaOH}$ hydrates, which also produces a sudden acceleration in reaction rate.

The frequency of temperature spikes may be reduced by removing liquid reaction products as they form, or by stopping the treatment process periodically to remove liquid pools. Removal of liquid by-products during the reaction process has an added benefit in exposing fresh residual sodium surfaces, and allows for reaction of residual sodium deposits to arbitrary depth. Care must be taken when removing liquid pools, since liquid removal may cause mixing, and this could lead to the uncontrolled reaction behavior that the draining step was intended to prevent.

In spite of these operational instabilities, the Steam-Nitrogen Process is rapid and has been used successfully for many years to deactivate residual sodium in industrial and nuclear 
systems. For example, E.I. DuPont de Nemours, Inc., routinely uses the technique to clean residual sodium from sodium transport rail cars and tanker trucks. The Hallam Nuclear Power Facility, a sodium-cooled breeder reactor that operated from 1962 to 1964 in Lancaster County, Nebraska, U.S.A, used superheated steam and nitrogen to deactivate its residual sodium content when the Hallam Reactor was decommissioned (Atomics International, 1970). Superheated steam is being used at the shutdown Fermi 1 Reactor Facility in Frenchtown Charter Township, Michigan, U.S.A. for in-situ cleaning of systems and piping networks containing residual sodium and $\mathrm{NaK}$, and for treatment of sodiumcoated components (Goodman, 2009).

\subsection{Water Vapor Nitrogen (WVN) process}

In the Water Vapor Nitrogen (WVN) Process, nitrogen saturated water vapor or nitrogen at less than $100 \%$ humidity is injected into the system, and the water vapor in the injection gas reacts with residual sodium to form $\mathrm{NaOH}, \mathrm{NaOH}$ hydrates, and hydrogen gas. Unlike the Steam-Nitrogen Process, the treatment process is carried out below the boiling point of water and below the melting point of sodium, generally in the temperature range $20-90^{\circ} \mathrm{C}$. The treatment rate is influenced by the amount of water vapor in the system, the inventory of water dissolved in the $\mathrm{NaOH}$ hydrate layer, and by the thickness of the $\mathrm{NaOH}$ and $\mathrm{NaOH}$ hydrate layers.

The reaction products, $\mathrm{NaOH}$ and $\mathrm{NaOH}$ hydrates, are water-soluble, and may be removed from the treated system after the treatment process is complete by flushing the system with liquid water. Effluent from a water flushing step is highly basic due to dissolved $\mathrm{NaOH}$, and generally requires acid neutralization before further treatment and disposal.

Process conditions are selected to minimize the frequency and magnitude of temperature spikes. Water is delivered at a lower concentration to reduce the reaction rate and to allow more heat of reaction to dissipate per unit time. The residual sodium deposits are maintained below the melting point of sodium to minimize intermixing of sodium and water-rich liquids. Though pressure and temperature instabilities may still occur, pools of $\mathrm{NaOH}$ hydrates are removed when they accumulate to help prevent reaction instabilities. Like the Steam-Nitrogen Process, the WVN Process is capable of reacting residual sodium deposits to an arbitrary depth.

The chief practitioner of the WVN Process in the nuclear area is the United Kingdom Atomic Energy Authority, UKAEA, who is using the technique to clean systems containing residual sodium at its site in Dounreay (Gunn et al., 2009).

\subsection{Carbonation process}

The Carbonation Process is similar in execution to the WVN Process, except nitrogen is replaced with $\mathrm{CO}_{2}$, and this replacement greatly changes the process chemistry and characteristics of the treatment process. Like the WVN Process, hydrogen is produced as a by-product of the water-sodium reaction, as shown in Equation 1. Unlike the WVN Process, the $\mathrm{CO}_{2}$ carrier gas also participates as a reactant. In the presence of $\mathrm{CO}_{2}$ and at temperatures below $60^{\circ} \mathrm{C}, \mathrm{NaOH}$ produced by the water-sodium reaction is converted into sodium bicarbonate, $\mathrm{NaHCO}_{3}$, when it reacts with the $\mathrm{CO}_{2}$ carrier gas, as shown in Equation 3.

$$
\mathrm{NaOH}(\mathrm{s})+\mathrm{CO}_{2(\mathrm{~g})} \mathrm{g} \mathrm{NaHCO}_{3}(\mathrm{~s}) \quad \mathrm{T}<60^{\circ} \mathrm{C}
$$


$\mathrm{NaHCO}_{3}$ does not form liquid hydrates. Above $60^{\circ} \mathrm{C}, \mathrm{NaHCO}_{3}$ is unstable and disproportionates into sodium carbonate $\left(\mathrm{Na}_{2} \mathrm{CO}_{3}\right), \mathrm{CO}_{2}$, and water, as shown in Equation 4 .

$$
2 \mathrm{NaHCO}_{3}(\mathrm{~s}) \rightarrow \mathrm{Na}_{2} \mathrm{CO}_{3}(\mathrm{~s})+\mathrm{CO}_{2}(\mathrm{~g})+\mathrm{H}_{2} \mathrm{O}(\mathrm{g}) \quad \mathrm{T}>60^{\circ} \mathrm{C}
$$

$\mathrm{Na}_{2} \mathrm{CO}_{3}$ forms hydrates more readily than $\mathrm{NaHCO}_{3}$, but none of those hydrates are liquids. To avoid the formation of $\mathrm{Na}_{2} \mathrm{CO}_{3}$, the process is carried out at a temperature below $60^{\circ} \mathrm{C}$. The water content of the $\mathrm{CO}_{2}$ carrier gas is maintained at less than $100 \%$ humidity to avoid the condensation of liquid water in the system being treated. The treatment rate is influenced by the amount of water vapor in the system being treated, and the thickness of the $\mathrm{NaHCO}_{3}$ layer. Since the surface layer is solid, the mass transfer resistance for the diffusion of water vapor to the residual sodium surface is higher than for a liquid surface layer, and the reaction rate quickly becomes surface resistance limited once a $\mathrm{NaHCO}_{3}$ surface layer becomes established. Reaction of residual sodium to depths beyond $3-4 \mathrm{~cm}$ is possible but is very slow unless the thickness of the intervening $\mathrm{NaHCO}_{3}$ layer can be reduced or eliminated.

The reaction products, $\mathrm{NaHCO}_{3}$, is water-soluble, and may be removed from the treated system after the treatment process is complete by flushing the system with liquid water or another suitable solvent. The liquid effluent is only mildly basic, and may not require any further treatment before disposal. In the case that some amount residual sodium remains in the treated system after the Carbonation Process is stopped, the flush liquid would react with residual sodium to form $\mathrm{NaOH}$, but this $\mathrm{NaOH}$ will be buffered to some extent by the presence of dissolved $\mathrm{NaHCO}_{3}$.

$\mathrm{NaHCO}_{3}$ accumulates as a porous, solid layer on residual sodium surfaces. According to laboratory observations (Sherman et al, 2002), the thickness of the $\mathrm{NaHCO}_{3}$ layer is approximately 5 times the thickness of the sodium layer consumed. The volumetric expansion of the surface layer in relation to the volume of residual sodium can cause problems in areas where there is insufficient void space to accommodate growth, such as in small diameter piping. In such places, the void space can become filled with $\mathrm{NaHCO}_{3}$, thus blocking the flow path for humidified $\mathrm{CO}_{2}$ at that location. Examples of sodium samples treated with humidified carbon dioxide are shown in Figure 5.
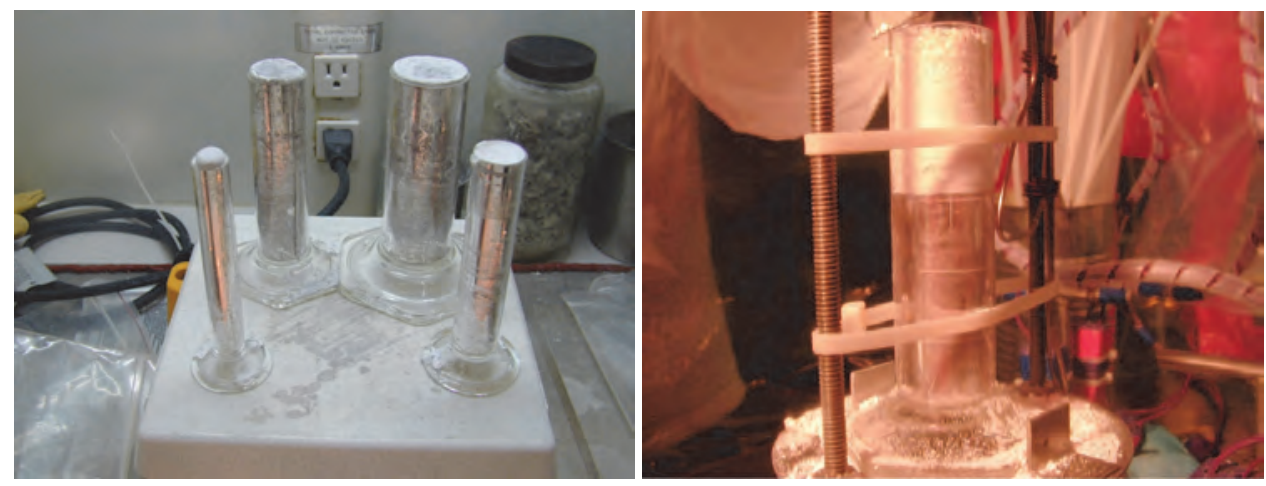

Fig. 5. Sodium samples before (left) and after (right) exposure to humidified $\mathrm{CO}_{2}$. In the figure on the right, the $\mathrm{NaHCO}_{3}$ layer is visible as a white layer above darker gray sodium metal. 
Unlike the Steam-Nitrogen and WVN Processes, the Carbonation Process is less subject to uncontrolled fluctuations in reaction rate. Under normal operating conditions, moisture does not accumulate in the $\mathrm{NaHCO}_{3}$ surface layer, so there is little opportunity for contact between residual sodium and accumulated aqueous solutions. Fluctuations in reaction rate and temperature are still possible if moisture condenses in the system being treated, but this may be avoided by using a sub-saturated treatment gas, or by heating the system that contains residual sodium, so that the atmospheric temperature within the system is higher than the treatment gas.

\subsection{EBR-II treatment process selection}

The process of selecting a treatment method for residual sodium within EBR-II was contentious. One group, composed of the EBR-II reactor designers and former operators, favored the use of the Steam-Nitrogen Process or the WVN Process because these methods promised faster treatment rates and the ability to react residual sodium to greater depths. In addition, the nitrogen-based processes were familiar and backed by experience. They also feared that application of the relatively untested Carbonation Process to EBR-II would place the EBR-II systems into a state in which it would be more difficult and costly to clean up during facility decommissioning than would occur if a nitrogen-based process were used instead. As a back-up strategy, they favored doing nothing as being preferable to application of the Carbonation Process. After all, the empty EBR-II systems were stable and could be maintained indefinitely in this "safe storage" condition as long as required before full funding was available for facility decommissioning.

The other group, composed the engineers and project personnel who were assigned to perform the residual sodium clean-up task, recognized the weight of the first group's recommendations, but were compelled by project requirements and constraints to look for other treatment options. The option of waiting until sufficient funding was available for facility decommissioning was not possible because the RCRA permit compelled treatment. Treatment project funding was insufficient to decommission the facility, and sufficient funding to decommission the facility would not be available for the foreseeable future. The option of using a nitrogen-based process to clean EBR-II systems was studied, but the nitrogen-based methods are subject to fluctuations in temperature and pressure, and the project sponsor, the U.S. Department of Energy, was very risk-averse and had little tolerance for any potential event that might cause harm to personnel or equipment, or lead to an unintentional release of radioactive material to the environment.

A particular project concern with the nitrogen-based processes had to do with the operational characteristics of the method, and the project funding frequency. The project's mandate was to perform residual sodium clean-up as funding became available. Full funding was not available at the start of the project, and funding would be provided on a yearly basis across the time span of the project. This meant that there would be periods of activity, followed by periods where the project was waiting for funding and work on the EBR-II systems would cease. The nitrogen-based processes, however, demand a full commitment to the system being treated, and must be carried out to completion once the treatment process is started if system safety is to be maintained. Before a system is treated, it contains only residual sodium, and the configuration is safe and stable. After treatment is completed, the system (presumably) would contain no residual sodium, and the configuration would be safe and stable. During treatment, and in between active treatment periods, the system would be unstable due to the simultaneous presence of residual sodium and liquid $\mathrm{NaOH}$ hydrates, and an uncontrolled reaction event could 
occur at any time. Although stopping the flow of steam or water vapor to the system stops the active treatment process, a stable configuration is not achieved again until all of the residual sodium inventory is consumed.

The project really needed a residual sodium clean-up method that was capable, stable, and that could be started and stopped at will without creating additional hazards during periods of inactivity. Although untested on a large scale, the Carbonation Process met these criteria. Laboratory work indicated that the method was capable of reacting sodium to depths beyond $3 \mathrm{~cm}$, which is sufficient for a majority of the residual sodium locations in EBR-II. The method was very stable, and did not undergo process variations in temperature and pressure. The $\mathrm{NaHCO}_{3}$ layer generated by the treatment process did not accumulate liquid moisture, so that partially treated systems were nearly as safe as untreated systems due to the depletion of residual sodium inventories and the blanketing of residual sodium deposits with a layer of $\mathrm{NaHCO}_{3}$. Also, the concern that application of the Carbonation Process would block access to deeper residual sodium deposits was alleviated by test that showed that the $\mathrm{NaHCO}_{3}$ layer is water-soluble.

In the end, the treatment project team selected the Carbonation Process for these reasons. However, without budget constraints and with greater ability to weather uncontrolled reaction events, the project team might have selected a nitrogen-based process instead. The higher treatment rates and better penetration ability of those methods were recognized, but other project constraints prevented their selection. The Carbonation Process, while slower and less capable of reacting residual sodium to great depths, had many other favorable characteristics, and was compatible with the needs of the treatment project.

\section{EBR-II system preparation}

Preparation of the Primary Tank and Secondary Sodium Systems for residual sodium treatment involved installation of a large $\mathrm{CO}_{2}$ source tank, piping changes to the Secondary Sodium System, installation of treatment-related equipment and instrumentation, and changeover of the systems' atmospheres from argon to $\mathrm{CO}_{2}$. These preparations are described below.

\section{1 $\mathrm{CO}_{2}$ source tank}

A liquefied $\mathrm{CO}_{2}$ tank was installed in between the EBR-II Containment Dome and the Sodium Boiler Building, the building in which the Secondary Sodium System equipment was located (see Figure 2). The tank had a 6400-kg capacity, and was bolted to a concrete pad. The tank was sized to supply pure $\mathrm{CO}_{2}$ at a $135 \mathrm{slm}\left(5\right.$ standard $\left.\mathrm{ft}^{3} / \mathrm{min}\right)$ for 2 weeks without refill.

\subsection{EBR-II primary tank piping changes}

The EBR-II Primary Tank cover has 58 penetrations or ports through which various instruments, tools, and equipment assemblies were inserted during regular operation of the reactor. One port contained a device called the Failed Fuel Removal System, which had never been used or irradiated. This device was removed from the Primary Tank cover, and a vent pipe was installed in its place. An in-line HEPA filter was also installed to contain any radioactive particulate generated during the treatment process. A schematic of the EBR-II Primary Tank rupture disk and floating head tank remained operational during treatment in order to protect the system against larger overpressure events. 


\subsection{Secondary sodium system piping changes}

After the bulk sodium was drained from the Secondary Sodium System, the piping network was altered to allow for the creation of 12 distinct linear flow paths through the system. Without distinct flow paths, sufficient flow of treatment gases through certain pathways could not be guaranteed due to the highly parallel nature of the pipe network. The flow paths were not exclusive, however, and there was some overlap between flow paths. A gas entry manifold was installed that allowed for seven different flow configurations for treatment gas. A vent manifold was also installed. Additional valves and tubing were also installed. The distinct flow paths were created by opening and closing valves in the inlet manifold, the vent manifold, and within the Secondary Sodium System. The exhaust end of the vent manifold was attached to a HEPA filter before exiting to a facility stack. The modified network of valves and pipes is shown in Figure 3.

\subsection{Additional equipment and instrumentation}

\subsubsection{Humidification cart}

A mobile $\mathrm{CO}_{2}$ humidification system, the Humidification Cart, was built to facilitate application of humidified $\mathrm{CO}_{2}$ at multiple locations. The Humidification Cart consists of a 170 liter clear acrylic water tank, four stainless steel frit bubblers, and a collection of Swagelok ${ }^{\mathrm{TM}}$ valves and tubing that allow a pressurized supply of $\mathrm{CO}_{2}$ to be humidified between 0 and $100 \%$. The tank and other equipment are placed on a wheeled platform, which gives it mobility, and the inlet and outlet gas connections are made using flexible tubing. The water tank is equipped with a bayonet heater with thermostatic control. The humidity of the treatment gas is measured using a GE Panametrics Moisture Meter with Remote Moisture Probe, Model \#MCHTR-1, which is installed in the $\mathrm{CO}_{2}$ exit flow path, and the flow rate of $\mathrm{CO}_{2}$ is measured using a simple glass bead rotometer. A schematic of the Humidification Cart is shown in Figure 6 and images of the Humidification Cart are shown in Figure 7.

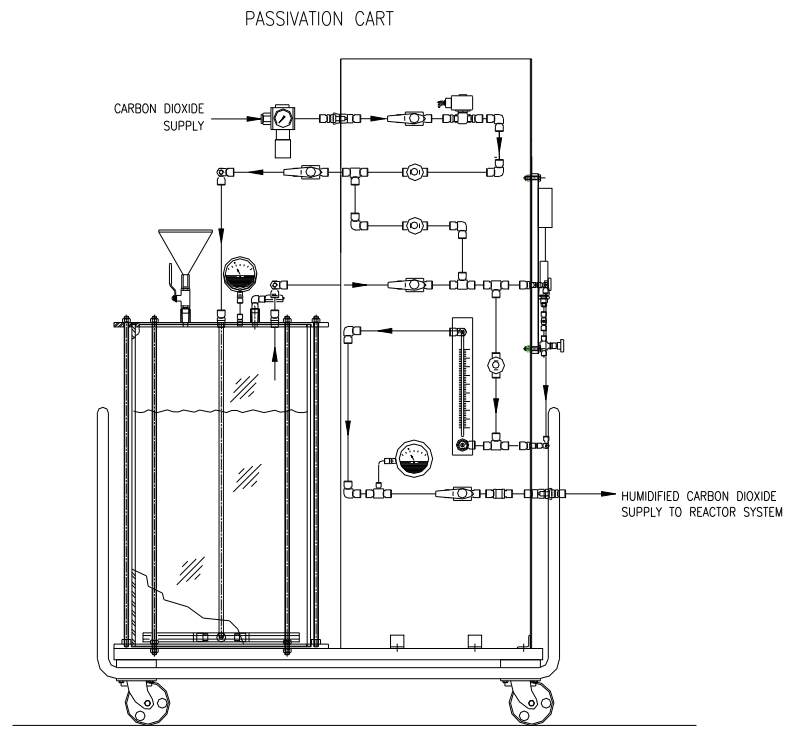

Fig. 6. Schematic of Humidification Cart. 

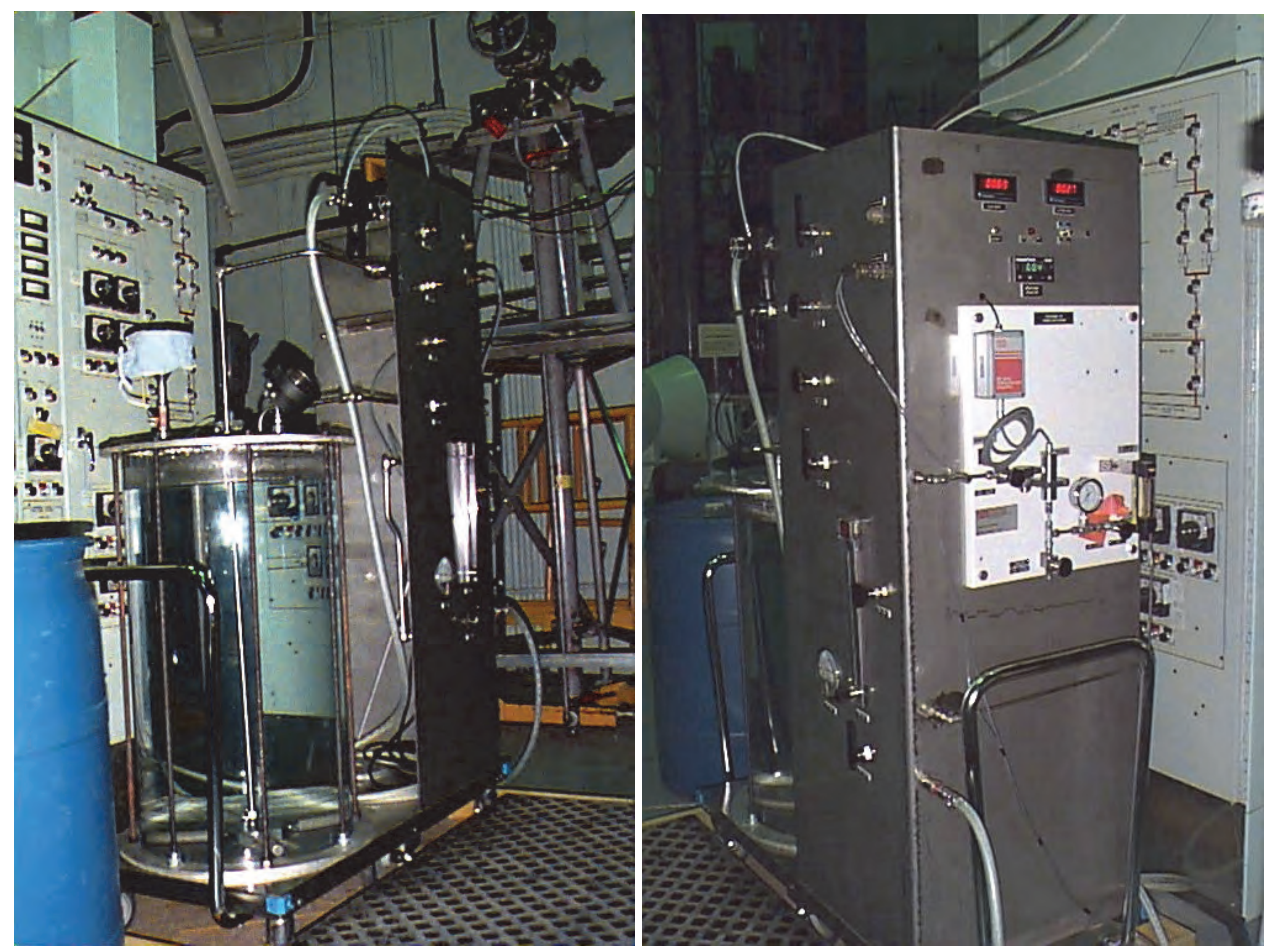

Fig. 7. Photos of the Humidification Cart's acrylic tank and instrumentation/valve panel.

\subsubsection{Instrumentation and controls}

Instrumentation and controls were installed on the Primary Tank vent line. A $5.08 \mathrm{~cm}\left(2^{\prime \prime}\right)$ Jordon Mark 518 low pressure spring-loaded mechanical back pressure regulator was installed in order to prevent the back-flow of air from the vent into the EBR-II Primary Tank. The back pressure regulator was normally closed, and opened only when the pressure inside Primary Tank exceeds 125 Pa-gage. A Teledyne Analytical Instruments \#326RB oxygen probe was also installed in order to detect air leakage into the Primary Tank, and the monitor was calibrated to read accurately in the range between $0-1 \mathrm{vol} \%$. A Fluid Components International $5.08 \mathrm{~cm}\left(2^{\prime \prime}\right)$ Model GF92 thermal dispersion mass flow meter with flow transmitter was installed to measure the mass flow rate of the exhaust gas and the exhaust gas temperature. A Teledyne Analytical Instruments \#235B thermal conductivity meter was installed to measure the hydrogen concentration in the exhaust gas, and was calibrated to read accurately in the range between 0-4 vol\%. A GE Panametrics Moisture Monitor with remote moisture probe, Model \#MCHTR-1, was also installed to measure relative humidity of the exhaust gas. The signal outputs from the mass flow meter, oxygen monitor, hydrogen monitor, and humidity monitor were recorded by a facility digital data acquisition system.

The Secondary Sodium System was not as thoroughly instrumented. Oxygen and hydrogen monitors of the same make and model as used on the EBR-II Primary Tank vent line were installed on the Secondary Sodium System vent, and no other instruments or pressure control devices were installed. 


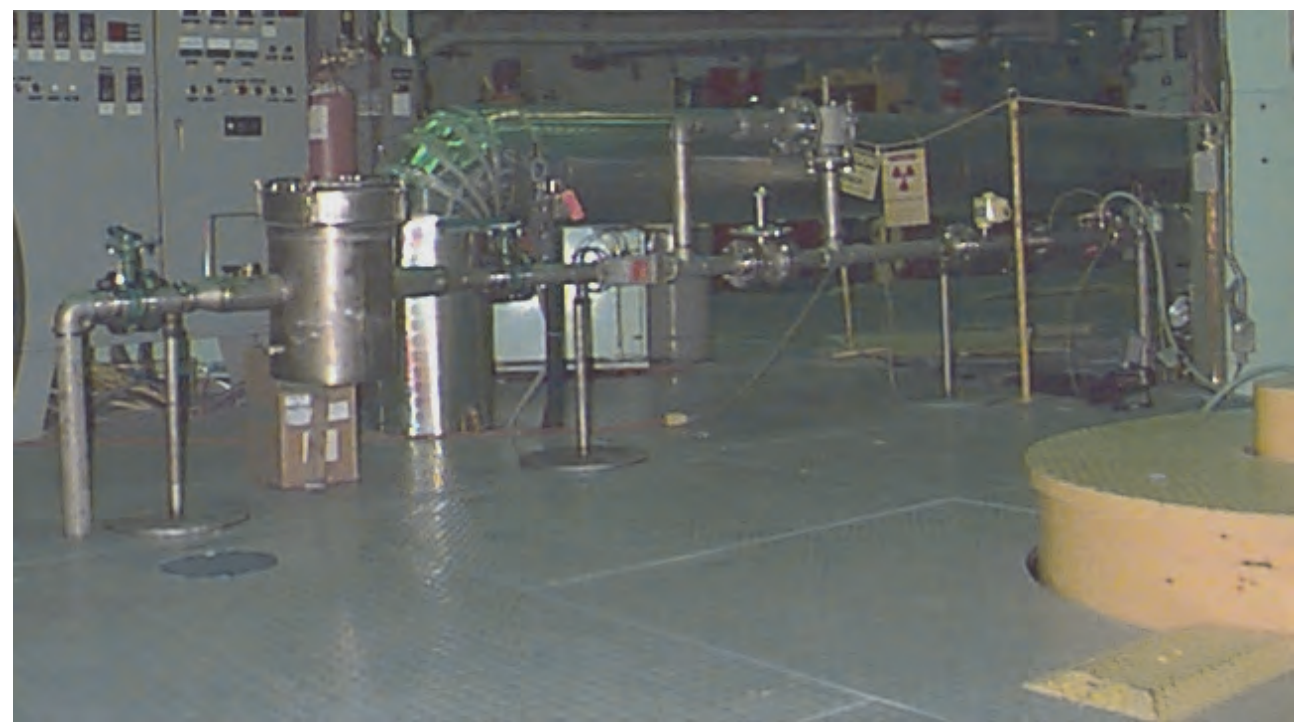

Fig. 8. Vent line for EBR-II Primary Tank with installed instrumentation and HEPA filter.

\subsection{Changeover of system cover gas from argon to $\mathrm{CO}_{2}$}

During regular operation, the EBR-II systems were blanketed with argon to protect the sodium coolant against exposure to oxygen. The Carbonation Process requires an internal atmosphere rich in $\mathrm{CO}_{2}$, and so the argon cover gas was changed to $\mathrm{CO}_{2}$ prior to beginning treatment. The cover gas changeover was accomplished by actively purging the argon blanket with a flow of dry, pure $\mathrm{CO}_{2}$. The Primary Tank was purged for 11 days, and the Secondary Sodium System was purged for 4 days with all valves open, at a $\mathrm{CO}_{2}$ flow rate of 135 standard liters/minute. These purge times were calculated to be sufficient to replace $99 \%$ of the argon atmosphere with $\mathrm{CO}_{2}$ with perfect mixing.

\section{Carbonation of residual sodium}

The Carbonation Process had never been used before to treat residual sodium within a nuclear reactor's cooling system, and there was no prior operating experience on which to draw. So, the project team decided to pilot the treatment method in the Secondary Sodium System before applying it to the Primary Tank. Although less instrumented, the Secondary Sodium System was accessible, and could be examined to learn more about the in-situ behavior of the treatment method. Also, if the treatment method created some unexpected condition that prevented further in-situ treatment, then the system could be disassembled and treated piecewise at SCMS.

This section describes the application of the Carbonation Process first to the Secondary Sodium System, and then to the Primary Tank.

\subsection{Treatment of secondary sodium system}

The treatment of the Secondary Sodium System was performed in two phases. The first phase involved the flow of treatment gas through various paths for time periods ranging 
between 1 and 19 days. The second phase involved a longer treatment period for the flow path containing Superheater 712. The flow path containing Superheater 712 was relatively simple with few sections of narrow pipe, and a deep pool (depth $>29 \mathrm{~cm}$ ) of residual sodium sat in the bottom of Superheater 712, which would allow for a more severe test of the treatment method than would be possible in other parts of the system.

Progress of the treatment process was determined by converting the measured hydrogen concentration data into a molar flow rate, integrating the hydrogen molar flow rate data with respect to time to provide the total amount of hydrogen generated, and then converting this number into the amount of residual sodium consumed using Equation 1. In this calculation, the exhaust gas flow rate was assumed to be equal to the input gas flow rate, and the exhaust gas was assumed to have ideal gas properties. Based on this calculation method, approximately $182 \mathrm{~kg}$ ( 190 liters) of residual sodium were consumed during treatment of the Secondary Sodium System. This amount is approximately $50 \%$ of the starting inventory of residual sodium.

The water level in the humidification cart was also monitored, and the volume of water evaporated was used to calculate an upper bound on the amount of sodium that could be reacted if $100 \%$ of the water evaporated from the Humidification Cart were consumed by the water-sodium reaction. This number is only an upper bound, however, since $100 \%$ consumption of water vapor becomes unlikely once a $\mathrm{NaHCO}_{3}$ surface layer becomes established. Based on this second calculation method, a maximum of approximately $300 \mathrm{~kg}$ ( $\sim 310$ liters) of residual sodium could have been consumed during treatment of the Secondary Sodium System. The discrepancy between the hydrogen-based residual sodium estimate and the upper bound estimate would occur if $\sim 1 / 3$ of the water evaporated from the Humidification Cart passed through the Secondary Sodium System without reacting.

\subsubsection{Secondary sodium system treatment phase one}

Phase One treatment of the Secondary Sodium System occurred over 64 days. Treatment occurred by flowing room temperature humidified $\mathrm{CO}_{2}$ into the system at a rate of approximately 135 standard liters/minute. A trace of the measured hydrogen concentration in the exhaust gas is shown in Figure 9.

The response of the system during treatment was very stable, and no uncontrolled or runaway reactions occurred due to the build-up of liquid water within the system. The graph shows spikes in hydrogen concentration, but these spikes were aberrations and correspond to time periods when the system valves were changed to alter the flow path of treatment gases. The dip in hydrogen concentration on Day 8 corresponds to a time period when the treatment gas was temporarily changed to dry $\mathrm{CO}_{2}$ to put more water in the tank on the humidification cart, and treatment was easily resumed without hysteresis in the system response. The concentration of hydrogen gas remained below $1 \mathrm{vol} \%$ during the length of the treatment period, which is below the lower flammability limit of hydrogen in air, $4 \mathrm{vol} \%$. At Day 64 , the gas flow was switched back to dry $\mathrm{CO}_{2}$ while maintaining a constant flow rate, and the hydrogen concentration in the exhaust gas decayed to $0 \mathrm{vol} \%$ as hydrogen was purged from the system.

Table 2 shows the treatment duration per path, and the amount of residual sodium reacted in each pathway based on an integration of the measured hydrogen concentration data. Taking into account the measured hydrogen concentration, approximately $92 \mathrm{~kg}$ of residual sodium, or about 95 liters, were consumed during the treatment period. In converting the measured hydrogen concentration into the amount of residual sodium consumed, the 
following conditions were applied: constant flow rate of 135 standard liters/minute, ideal gas conditions, and the assumption that 0.5 moles of $\mathrm{H}_{2}$ are produced for every 1.0 mole of residual sodium consumed.

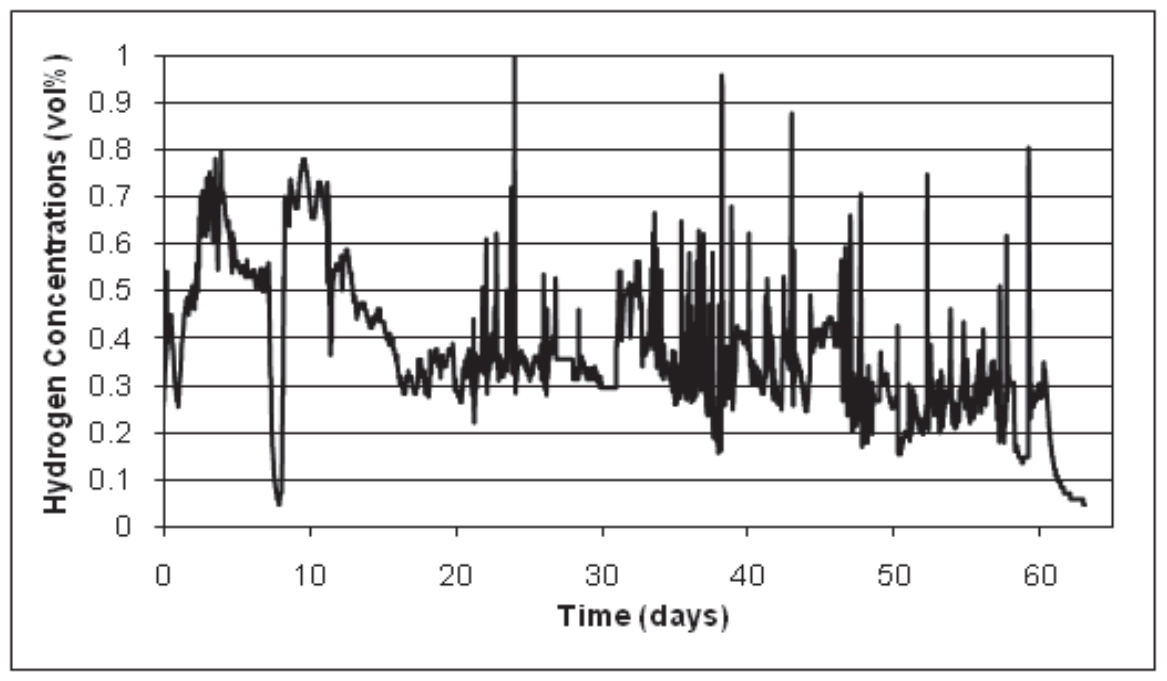

Fig. 9. Measured hydrogen concentration in exhaust gas during treatment of Secondary Sodium System.

\begin{tabular}{|c|c|c|}
\hline Path Name & $\begin{array}{l}\text { Treatment } \\
\text { Time } \\
\text { (days) }\end{array}$ & $\begin{array}{c}\text { Sodium Reacted, } \\
\mathrm{kg} \\
\left(\mathrm{H}_{2} \text { basis }\right)\end{array}$ \\
\hline Surge Tank to Yard Lines & 19.0 & 32 \\
\hline Superheater 712 & 12.1 & 21 \\
\hline Secondary Flow Path to Yard Lines & 6.9 & 10 \\
\hline Line Na2-34-557 & 2.2 & 2 \\
\hline Major Purge - Superheaters and Evaporators & 1.9 & 2 \\
\hline Superheater 710 Purge & 4.1 & 6 \\
\hline Surge Tank & 1.0 & 1 \\
\hline North Evaporators (4 units) & 4.7 & 7 \\
\hline South Evaporators (3 units) & 1.3 & 1 \\
\hline Line Na2-31-534 & 1.0 & 1 \\
\hline Line Na2-31-536 & 1.0 & 1 \\
\hline Final Treatment of Surge Tank to Yard Lines & 3.8 & 4 \\
\hline $\begin{array}{l}\text { Final Treatment Evaporators, Superheaters, Line Na2- } \\
34-520\end{array}$ & 2.2 & 3 \\
\hline Final Purge with Dry $\mathrm{CO}_{2}$ & 2.8 & 1 \\
\hline Total & 64.0 & 92 \\
\hline
\end{tabular}

Table 2. Summary of treatment times and inventory of reacted residual sodium for Treatment Phase One. 
According to the experimental records, approximately 115 liters of water were evaporated during this treatment period, which is enough water to react approximately $145 \mathrm{~kg}$, or about 155 liters, of residual sodium if all of that water came into contact with residual sodium. Since the hydrogen-based residual sodium estimate is less than this number, some amount of water vapor must have passed through the system unreacted. Evidence that water vapor passed through the system unreacted was provided by observing the hydrogen monitoring system. The installed hydrogen monitor required a dry gas feed, and a refrigerated dehumidifier or gas conditioner was used to achieve this. As the treatment operation proceeded, liquid condensate began to accumulate in the gas conditioner's collection bottle, and at an increasing rate, as the treatment process continued. Since the only moisture input stream into the gas conditioner was exhaust gas from the Secondary Sodium System, collection of liquid condensate indicated that the exhaust gas water vapor

\subsubsection{Secondary sodium system treatment phase two}

Phase Two treatment was performed for 72 days, and involved the flow path that included Superheater 712. This flow path had previously been treated for a period of 12 days. The measured hydrogen concentration during this treatment period are shown in Figures 10 and 11. The treatment period is split into two parts, one spanning 8 days, and the other spanning 64 days. This division of the treatment period into two parts was not by design, but was caused by the formation of a blockage in a narrow section of pipe in an elbow at the top of Superheater 712. Physical examination of the blocked location revealed that the narrow pipe section had filled with white powder, which was later revealed by chemical tests to be $\mathrm{NaHCO}_{3}$. After formation of the blockage, a dry $\mathrm{CO}_{2}$ flow was initiated through other system pathways to flush hydrogen from the system, and then flexible plastic tubing was installed around the blocked section. Treatment of the Superheater 712 pathway was then resumed.

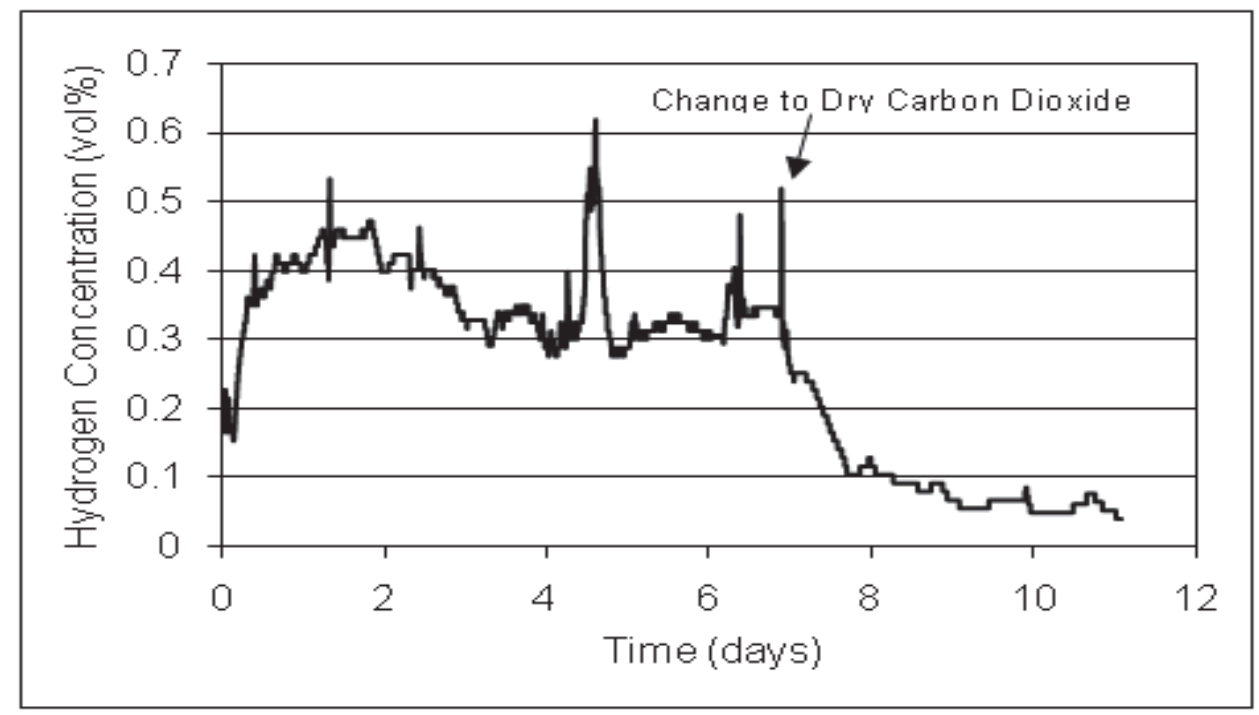

Fig. 10. Measured hydrogen concentration during Phase Two treatment of the Secondary Sodium System, first 8 days. 
The treatment process proceeded steadily with no uncontrolled reaction behavior. In Figure 11 , there is a large spike in hydrogen concentration on Day 5, but this spike was attributed to a power surge during a lightning storm which tripped the hydrogen monitor, and is not believed to be a true measurement at that point.

According to an integration of the measured hydrogen concentration, approximately $90 \mathrm{~kg}$ (< 95 liters) of residual sodium were consumed during Phase Two. Another 115 liters of water were evaporated during the treatment period also, and the excess water vapor was presumed to have been vented in the exhaust gas.

At the end of this treatment phase, the measured hydrogen concentration was still above 0.2 vol\%. A treatment endpoint was not reached at the end of Phase Two, and more residual sodium remains in this system that is accessible by the Carbonation Process.

\subsubsection{Post treatment examination of the secondary sodium system}

A physical examination of Superheater 712 and sections of piping along the Superheater 712 flow path were performed in order to verify the effects of the treatment process. For Superheater 712, the level of residual sodium metal in the bottom of the superheater before and after treatment was determined by hitting the side of the superheater with a hammer and listening for a change in the sound of the hammer blows. According to this test, the residual sodium within the superheater had been reacted to a depth of approximately 2.5 $\mathrm{cm}$. After treatment, a $1.3 \mathrm{~cm}$ diameter hole was drilled approximately $25 \mathrm{~cm}$ above the measured residual sodium level, and a boroscope was inserted into the superheater to look at the top of the surface layer and other superheater internals. The visual inspection revealed that the surface layer had grown upward in the open space above the residual sodium deposit. A metal support framework affected the growth of the layer, and the layer had expanded upward through the support framework to form white stalagmites. The stalagmites were solid but brittle, and had little mechanical strength when pushed by the boroscope.

In another section of the system, a pipe "T" containing a known amount of residual sodium was drilled and examined using the boroscope. The visual inspection showed a similar looking white layer of material on top of the residual sodium deposit. Residual sodium at this location had also been reacted to a depth of $2.5 \mathrm{~cm}$. Samples of white material obtained at this location were tested chemically by titration and x-ray diffraction, and it was identified as pure $\mathrm{NaHCO}_{3}$.

\subsubsection{Lessons learned from treatment of secondary sodium system}

The Carbonation Process proved to be a safe and effective means of reacting residual sodium in areas where the residual sodium deposits were shallow, and where there was sufficient void space to accommodate growth of the $\mathrm{NaHCO}_{3}$ layer. The behavior of the treatment process in the Secondary Sodium System was similar to what was experienced earlier in the laboratory when test samples were exposed. According to the visual inspections, the method appeared capable of reacting residual sodium to similar depths at widely separated locations, even in complex piping systems. Measurement of hydrogen concentration in the exhaust is the best means available to track treatment progress in systems that cannot be inspected visually during the treatment process. Further treatment of the Secondary Sodium System is needed before RCRA clean closure status may be achieved. Since the treatment process was slow and could be monitored electronically, the process could be operated with minimal supervision and maintenance. 


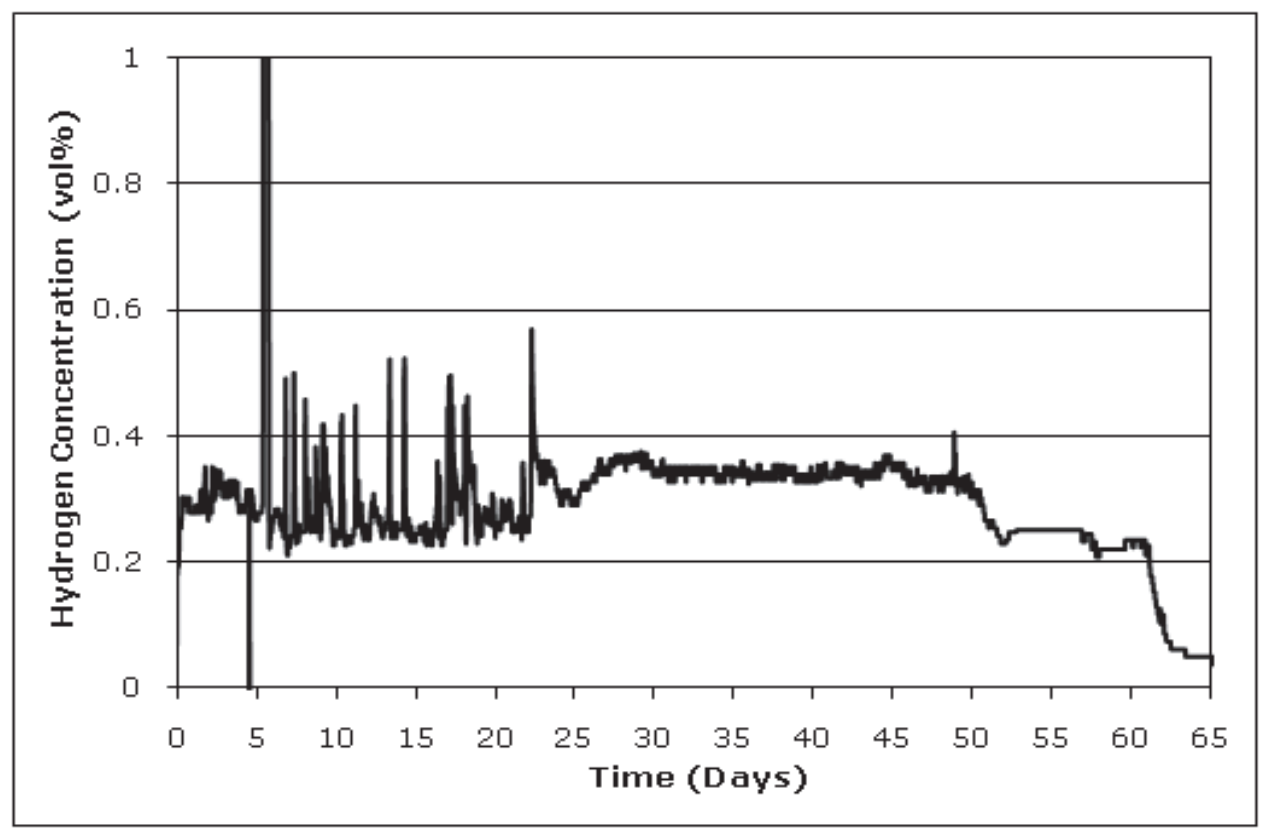

Fig. 11. Measured hydrogen concentration during Phase Two treatment of the Secondary Sodium System, last 64 days.

\subsection{Treatment of EBR-II primary tank}

Treatment of the EBR-II Primary Tank occurred over a cumulative period of approximately 660 days. This treatment period was not continuous, and was interrupted by occasional maintenance periods lasting from days to weeks where the flow of humid carbon dioxide was stopped. During these maintenance periods, the Primary Tank was placed in a no-flow static condition under a dry $\mathrm{CO}_{2}$ atmosphere. It is estimated that approximately $760 \mathrm{~kg}$, or 780 liters, of residual sodium was converted into $\mathrm{NaHCO}_{3}$ by the Carbonation Process, as determined by an integration of the hydrogen concentration data in the exhaust gas. This amount is approximately $70 \%$ of the starting inventory of residual sodium in the EBR-II Primary Tank. Although the amount of residual sodium consumed could not be verified by visual inspection, integration of the hydrogen concentration data over time provided an indirect method of assessing this number. This calculation was made more accurate by also taking into account the measured exhaust gas mass flow rate, exhaust gas temperature, and the measured concentrations of oxygen and water vapor in the exhaust gas. As was done with the Secondary Sodium System, the exhaust gas was assumed to have ideal gas properties.

The measured reaction rates appear to correspond to treatment rates that would be expected if the following conditions were met: uniform internal distribution of the treatment gas, surface control of the water-sodium reaction rate, and accurate representation of the residual sodium deposit physical geometry and configuration, as described in Section 2.1. A model of the reaction process was prepared to predict treatment rates, and a comparison of the measured and modeled treatment rates showed good agreement, especially after the $\mathrm{NaHCO}_{3}$ surface layer becomes established. 


\subsubsection{Initial system treatment}

Initially, the EBR-II Primary Tank was treated over a period of 55 days in order build confidence that the treatment process could be used safely and effectively on the EBR-II Primary Tank. Treatment occurred by flowing either room temperature or heated humidified $\mathrm{CO}_{2}$ into the system at a rate of approximately 135 standard liters/minute. The treatment gas was introduced to the Primary Tank through a pipe that was inserted through a nozzle in the Primary Tank cover and extending downward to within $0.95 \mathrm{~cm}$ from the bottom of the tank. Placement of the pipe exit at the bottom of the tank was believed to enhance gas mixing, since the vent for the tank was installed at the top of the vessel. Figure 12 shows the measured hydrogen concentration and relative humidity in the Primary Tank exhaust gas during the first 55 days of treatment. Initially, the temperature of the water tank was allowed to drift with the temperature of the room. During the last 20 days in the Figure, the water tank was heated to approximately $35-40^{\circ} \mathrm{C}$ in order to increase the moisture content of the treatment gas. Increasing the water tank temperature resulted in an increase in the measured hydrogen concentration, and also in the relative humidity of the exhaust gas. The drop in hydrogen concentration on Days 20-24 occurred when treatment was temporarily stopped in order to refill the $\mathrm{CO}_{2}$ supply tank. The treatment gas flow was changed again from humidified $\mathrm{CO}_{2}$ to dry $\mathrm{CO}_{2}$ at Day 54, and this change is reflected by the sharp decline in the measured relative humidity and hydrogen concentration on Day 55.

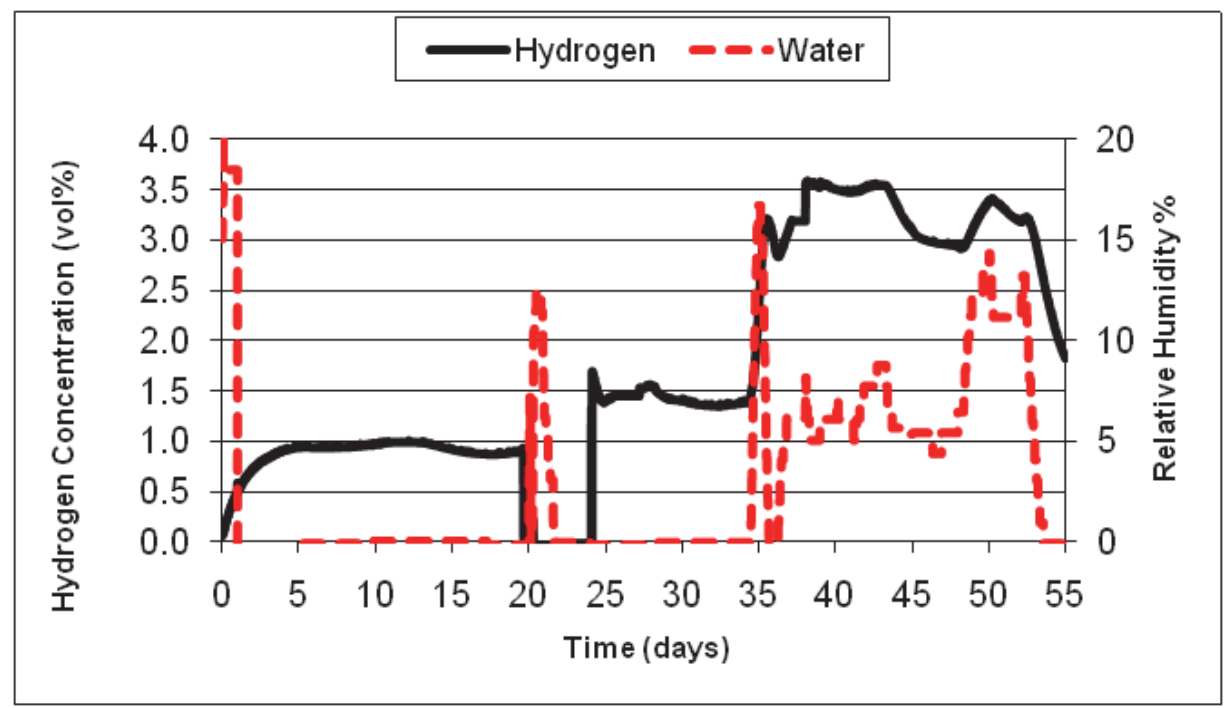

Fig. 12. Measured hydrogen concentration and relative humidity during first 55 days of treatment.

During this initial treatment period, it is estimated that approximately $150 \mathrm{~kg}$ of residual sodium was reacted based on the amount of water evaporated from the Humidification Cart. Although using the water tank level to determine the amount of residual sodium reacted generally produces treatment numbers that are too high, an integration of the hydrogen data for the last 30 days of this treatment period gave an even higher number than would have been possible based on a water mass balance. This discrepancy was 
investigated, and two potential causes were identified: either the record of the amount of evaporated was incorrect, or the calibration on the hydrogen monitor was incorrect, and it was reading too high. No proof was found to confirm either suspicion, so it was decided to err on the side of caution and use the lower residual sodium estimate for this treatment period.

\subsubsection{Extended system treatment}

After the initial treatment period, treatment of the Primary Tank was stopped for almost two years while awaiting further funding. During this waiting period, the Primary Tank was placed in a static condition under a dry $\mathrm{CO}_{2}$ blanket.

Treatment was eventually resumed using the same treatment operating conditions as used previously, and was carried out for another 600 days. The hydrogen concentration and exhaust gas mass flow rate measured during this treatment period are shown in Figure 13.

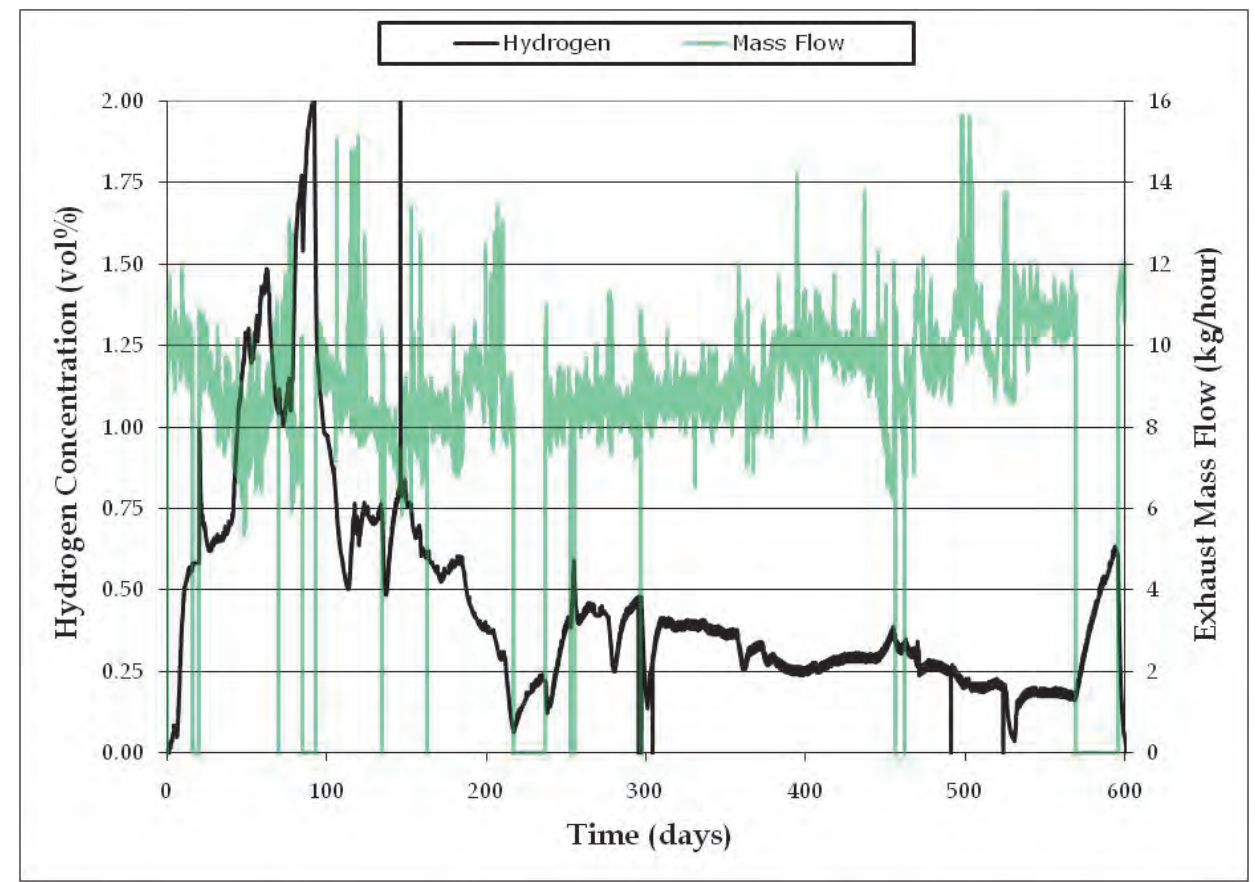

Fig. 13. Measured hydrogen concentration and exhaust gas mass flow rates during last 600 days of treatment.

In the figure, the hydrogen concentration peaked at about $2 \mathrm{vol} \%$ on Day 80 , and then declined over the remaining treatment period to less than $0.25 \mathrm{vol} \%$. The measured mass flow rate was never steady, and the variability in the measured exhaust mass flow rate is believed to arise from fluctuations in the opening of the mechanical back-pressure regulator. During this treatment period, another $630 \mathrm{~kg}$ of residual sodium were estimated to have been consumed. Treatment of the Primary Tank was stopped after 600 days due to declining treatment rates, and no natural process endpoint had been reached. The decline in treatment rate was 
accompanied by an increase in the humidity in the exhaust gas, and humidity levels measured greater than $70 \%$ in the exhaust gas by the end of the treatment period.

\subsubsection{Treatment rate model and correlation to measured data}

The reaction rate model was developed during the initial testing stages (Sherman et al., 2002) of the treatment method. The model is defined by a list of rules. The rules are as follows.

1. Due to uniform mixing, moisture is evenly distributed to all exposed residual sodium surfaces. Treatment of residual sodium at multiple locations occurs in parallel.

2. When the surface layer is less than $0.5 \mathrm{~cm}$ thick, the residual sodium reaction rate equals the moisture injection rate.

3. When the surface layer thickness is greater than or equal to $0.5 \mathrm{~cm}$, the reaction rate becomes surface-limited. The flux of water vapor to the residual sodium surface is inversely proportional to the surface layer thickness, and is directly proportional to the moisture input rate. The overall residual sodium reaction rate is equal to the moisture flux times the available residual sodium surface area.

4. There is no discontinuity in the reaction rate when the surface layer thickness equals 0.5 $\mathrm{cm}$, and surface-limited reaction rate equals the moisture input rate.

5. For every unit volume of residual sodium reacted, approximately 5 unit volumes of $\mathrm{NaHCO}_{3}$ are created.

6. A residual sodium deposit becomes unavailable for further reaction when it is fully consumed or the void space above a deposit becomes completely filled with the $\mathrm{NaHCO}_{3}$ (i.e., access to the residual sodium deposit by treatment gas is blocked).

Application of the model to the EBR-II Primary Tank required further definition of the physical configuration of the residual sodium deposits. The residual sodium at each location varies in depth, mass, and exposed surface area. Some deposits are relatively shallow and spread over a wide area, while other deposits are deep and have only a small area of exposed surface. Other deposits are located deep within equipment and have no exposed surface area. Table 3 provides information about the accessible residual sodium locations, and the locations are arranged in decreasing order in regard to the ability of the treatment method to react residual sodium at each location. In Table 3, the Location \# corresponds to the subset of locations that are considered accessible by the Carbonation Process (see Table 1). The "Vol" column lists the residual sodium volume at each location. The "Deposit Mass" column lists the mass of residual sodium found at each location. The "Avail Area" column lists the exposed surface area of the residual sodium deposit at each location before treatment.. The "Depth 1" through "Depth 6" columns provide the masses of residual sodium residing within the defined treatment depths for each location. The "Done?" column provides a logical descriptor to show whether complete treatment of a location might be achieved in a finite amount of time. The number marked "Start" shows the beginning mass of residual sodium residing at the subset of locations selected for Table 3, and the "End" number shows the total amount of residual sodium that remains after residual sodium has been reacted to a depth of $3.8 \mathrm{~cm}$ (Depth 6). The available surface area shows the exposed surface area at each treatment depth range, assuming that the exposed residual sodium surface area at each location remains constant until all residual sodium at a particular location is consumed or becomes blocked due to the buildup of $\mathrm{NaHCO}_{3}$. 


\begin{tabular}{|c|c|c|c|c|c|c|c|c|c|c|}
\hline $\begin{array}{c}\text { Location } \\
\#\end{array}$ & $\begin{array}{c}\text { Vol, } \\
\text { (L) }\end{array}$ & $\begin{array}{c}\text { Deposit } \\
\text { Mass, } \\
(\mathrm{kg})\end{array}$ & $\begin{array}{c}\text { Avail. } \\
\text { Area, } \\
\left(\mathrm{m}^{3}\right)\end{array}$ & \begin{tabular}{|c|} 
Depth 1 \\
$<0.1$ \\
$\mathrm{~cm}$ \\
$(\mathrm{~kg})$ \\
\end{tabular} & \begin{tabular}{|c|} 
Depth 2 \\
$0.1-0.38$ \\
$\mathrm{~cm}$ \\
$(\mathrm{~kg})$ \\
\end{tabular} & \begin{tabular}{|c|} 
Depth 3 \\
$0.38-$ \\
$0.95 \mathrm{~cm}$ \\
$(\mathrm{~kg})$ \\
\end{tabular} & \begin{tabular}{|c|} 
Depth 4 \\
$0.95-3.18$ \\
$\mathrm{~cm}$ \\
$(\mathrm{~kg})$ \\
\end{tabular} & \begin{tabular}{|c|} 
Depth 5 \\
$3.18-$ \\
$3.65 \mathrm{~cm}$ \\
$(\mathrm{~kg})$ \\
\end{tabular} & \begin{tabular}{|c|} 
Depth 6 \\
$3.65-3.8$ \\
$\mathrm{~cm}$ \\
$(\mathrm{~kg})$ \\
\end{tabular} & Done? \\
\hline 24 & 189 & 183 & 50.0 & 49 & 130 & --- & --- & --- & --- & Yes \\
\hline 23 & 473 & 456 & 50.0 & 49 & 130 & 270 & --- & --- & --- & Yes \\
\hline 1 & 27 & 26 & 0.9 & 0.82 & 2.3 & 4.7 & 18.2 & --- & --- & Yes \\
\hline 2 & 125 & 121 & 1.5 & 1.4 & 3.9 & 8.0 & 31.2 & 6.7 & blocked & No \\
\hline 14 & 11 & 11 & 0.1 & 0.08 & 0.2 & 0.5 & 1.9 & 0.4 & 0.13 & No \\
\hline 3 & 117 & 113 & 1.2 & 1.2 & 3.5 & 7.0 & 27.3 & 5.8 & 1.9 & No \\
\hline 4 & 42 & 41 & 0.9 & 0.83 & 2.3 & 4.7 & 18.4 & 3.9 & 1.3 & No \\
\hline 7 & 11 & 11 & 0.2 & 0.24 & 0.7 & 1.4 & 5.4 & 1.2 & 0.38 & No \\
\hline 8 & 11 & 11 & 0.1 & 0.15 & 0.4 & 0.8 & 3.2 & 0.7 & 0.23 & No \\
\hline 16 & 8 & 8 & 0.1 & 0.12 & 0.3 & 0.5 & 2.65 & 0.56 & 0.19 & No \\
\hline 21 & 2 & 2 & 0.0 & 0.0 & 0.1 & 0.2 & 0.65 & 0.14 & 0.05 & No \\
\hline \multicolumn{2}{|c|}{ Subtotal, $(\mathrm{kg})$} & $\begin{array}{c}\text { Start } \\
982\end{array}$ & & 103 & 282 & 301 & 109 & 19 & 4 & $\begin{array}{l}\text { End } \\
164\end{array}$ \\
\hline \multicolumn{4}{|c|}{ Available Surface Area, $\left(\mathrm{m}^{3}\right)$} & 105.0 & 105.0 & 55.0 & 5.0 & 4.1 & 2.6 & \\
\hline
\end{tabular}

Table 3. Masses and available surface areas for residual sodium deposits arranged according to treatment depth.

The depth ranges are interpreted sequentially. At the start of treatment, there is no $\mathrm{NaHCO}_{3}$ surface layer, and treatment proceeds as quickly as moisture can be introduced. Once the treatment process has penetrate to a depth of $0.1 \mathrm{~cm}$ (Depth 1), the surface layer thickness reaches $0.5 \mathrm{~cm}$ (see Rule 5 above), and the water-sodium reaction rate becomes surfacecontrolled. At a treatment depth of $0.38 \mathrm{~cm}$ (Depth 2), all of the residual sodium on the bottom of the Primary Tank cover has been reacted, and the total residual sodium surface area is reduced accordingly. At a treatment depth of $0.95 \mathrm{~cm}$ (Depth 3), the residual sodium on the bottom of the Primary Tank has been reacted, and that surface no longer serves a moisture sink. At a treatment depth of $3.18 \mathrm{~cm}$ (Depth 4), the residual sodium located in the Low Pressure Plenum has been reacted, and the available residual sodium surface area is reduced again. At a depth of $3.65 \mathrm{~cm}$ (Depth 5), access to the residual sodium in the High Pressure Plenum becomes blocked, and that location becomes inactive. At a depth of $3.8 \mathrm{~cm}$ (Depth 6), the residual sodium located outside the flow baffle around the gripper/hold down becomes blocked by the build-up of $\mathrm{NaHCO}_{3}$, and that location becomes inactive. Reaction of additional amounts of residual sodium at Locations 3, 4, 7, 8, 16, and 21 are still possible if treatment is pursued to greater depths, and the piece-wise analysis of reaction depths would need to be continued if the reaction rate model were extended to deeper reaction depths.

Interpreting the information provided in Table 3, it is clear that complete consumption of residual sodium in the Primary Tank just isn't possible using the Carbonation Process. Only about $982 \mathrm{~kg}$ out of the total residual sodium inventory $(\sim 1100 \mathrm{~kg})$ are accessible. In addition, the treatment rate would be exceedingly slow at greater treatment depths due to loss of available surface area. At a treatment depth of $3.81 \mathrm{~cm}$, for example, $97.5 \%$ of the original residual sodium surface area has been eliminated, and the overall treatment rate is reduced proportionately if a constant moisture input rate is assumed. 
Average daily residual sodium treatment rates were calculated using the data shown in Figures 12 and 13, and these average treatment rates were plotted in Figure 14 as a function of the total amount of residual sodium treated. A model curve was also plotted based on the specific information provided in Table 3 and a fixed moisture input rate. During the initial treatment period, the measured data fall far below the model curve when the water tank in the Humidification Cart was unheated (first 20 days in Figure 12), but align more closely when the tank was heated (next 40 days, Figure 12). When treatment of the Primary Tank was resumed after the long hiatus, the measured points fluctuate around the model curve until approximately $400 \mathrm{~kg}$ of residual sodium had been consumed, and then the measured points align quite closely with the model curve. In the flat portion of the model curve (upper left), the rate is controlled by the moisture input rate, and the wide discrepancy between the measured data and the model curve is due to selection of the wrong moisture input rate for the model during the initial treatment period. Once the surface layer becomes ratecontrolling, the moisture input rate becomes less critical, and the measured data follow the model curve more closely. The growth in surface layer thickness and loss of available surface area, leads to large reductions in the treatment rate at higher treatment totals, and this effect is evidenced in the plot.

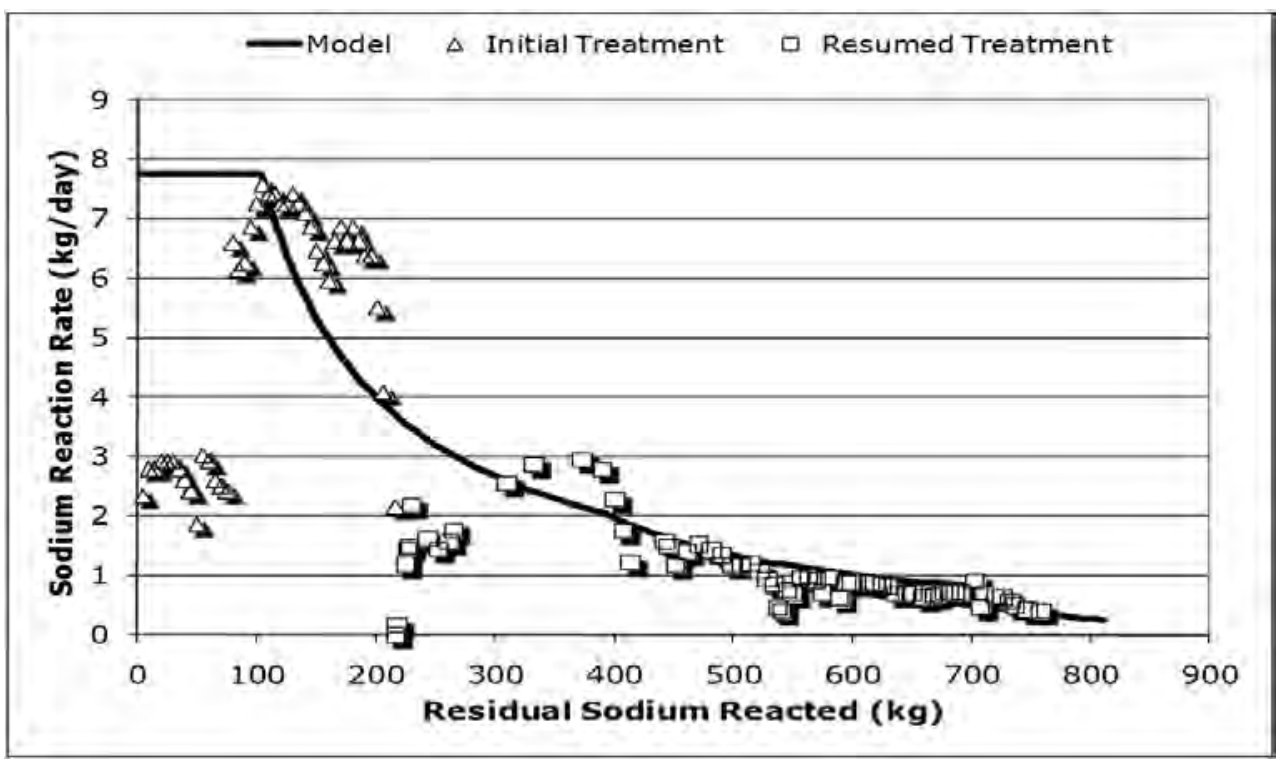

Fig. 14. Comparison of observed reaction rates versus modeled reaction rates as a function of the cumulative mass of residual sodium consumed.

\subsubsection{Lessons learned from treatment of EBR-Il primary tank}

The Carbonation Process may be stopped and started arbitrarily without causing changes in treatment performance if the system is placed in a dry, static condition in between treatment periods. The process performed smoothly over the extended treatment period without spikes in temperature or hydrogen concentration. Although complete treatment of residual 
sodium within the Primary Tank was not possible, application of the treatment method did result in a great reduction in the chemical reactivity of the remaining residual sodium by elimination of the easily accessible deposits, and burial of the deeper deposits beneath a thick layer of relatively inert $\mathrm{NaHCO}_{3}$. The treatment of residual sodium within the EBR-II Primary Tank using humidified $\mathrm{CO}_{2}$ might have been continued still further with the Carbonation Process, but the treatment process had reached the point of diminishing returns, and little further progress towards the treatment goal was anticipated if the treatment process were continued beyond the chosen stopping point.

\section{Conclusions and future work}

In one sense, application of the Carbonation Process to EBR-II in order to deactivate residual sodium was very successful. Approximately $70 \%$ of residual sodium within the EBR-II Primary Tank and 50\% of residual sodium within the EBR-II Secondary Sodium System were converted into relatively benign $\mathrm{NaHCO}_{3}$ with no safety problems. The treatment method was easy to use and could be started and stopped at will with no hysteresis effects. The residual sodium that remains within EBR-II is much less chemically reactive, and the systems are much better protected against uncontrolled air and water leaks. In addition, the behavior of the treatment process appears to be well understood and can be explained and predicted using a relatively simple rule-based model.

In another sense, however, using the Carbonation Process in order to achieve a clearly defined RCRA-closed state in the EBR-II systems was not a good strategy. Complete deactivation of all residual sodium within these could never be achieved, even with very long treatment times, and an additional treatment step is still required to remove the reaction by-product.

Considering the complex geometry of the residual sodium deposits in the EBR-II Primary Tank, it is not clear that using the Steam-Nitrogen Process or the WVN Process would have been much more successful. Though these methods may have been able to achieve greater depth penetration and faster reaction rates, eventually these methods too would become surface limited due to the build-up of liquid surface layers and consumption of the easier-toreach locations, and treatment rates would also have declined over time. In addition, achievement of a clearly defined RCRA-closed state would still have required a follow-on treatment step to remove the reaction by-products, and the desired endpoint could not be reached in a single treatment step.

At this point in time, it is still possible to meet the strict definition of RCRA closure in the Primary Tank if the tank were filled and flushed with liquid water. Filling the tank with liquid water would consume the remaining residual sodium and dissolve the reaction by-products.

Though the thought of adding liquid water to sodium metal may sound alarming, the safety aspects of the operation would be aided by the placement of the remaining residual sodium deposits. The locations still containing residual sodium reside at different heights in the Primary Tank, and the instantaneous reaction of all residual sodium would not occur if the Primary Tank were slowly filled with water. While residual sodium above the water level may react weakly in response to water vapor in the gas space above the liquid level, a strong sodium-water reaction would not occur until the liquid height reaches the height of a residual sodium deposit, or the liquid level becomes high enough to overcome a hydraulic barrier, causing water to overflow into a residual sodium location at a lower elevation. While it is certain that there would be some uncontrolled and episodic reaction behavior when liquid initially comes into contact with residual sodium, the rate of energy released 
would be limited by the available surface area of the residual sodium deposit, and not all of the residual sodium at a particular location would react instantaneously due to the reduced surface area of the deposit. Also, the mass of water in the tank would serve as a heat sink and would absorb the heat of reaction as water-sodium reactions occur.

Adding water to the Primary tank would generate a large volume of waste that would need to be handled, and the costs and safety aspects of handling this waste material must be balanced against the larger need to protect the environment, which is the original intent of the RCRA permit.

If process safety is the ultimate arbiter, then the best option to pursue at this point would be to seek a risk-based closure with no further treatment of residual sodium. The relative safety and environmental risks associated with the Primary Tank were much improved by application of the Carbonation Process, and there would be little risk of any uncontrolled sodium-water reactions occurring in the Primary Tank even if moist air leaked into the Primary Tank. As an added precaution, the Primary Tank may be also filled with grout to seal and immobilize the remaining residual sodium deposits, and block all further access to them.

It is this last option that the Idaho Clean-up Project (ICP), administered by $\mathrm{CH} 2 \mathrm{M}^{*} \mathrm{WG}$ Idaho, the current organization overseeing stewardship of the EBR-II facility, has selected to pursue. By 2015, the company plans to fill the Primary Tank with grout, to further isolate the remaining reactor internals, and leave it in place. Although the Carbonation Process was not successful in reacting all of the residual sodium within the EBR-II Primary Tank, it worked well enough to allow for a risk-based closure without requiring further treatment of residual sodium.

\section{References}

Atomics International. Report on Retirement of Hallam Nuclear Power Facility. AI-AEC12709, May 15, 1970. Available from Library of Congress, Technical Reports and Standards, U.S.A.

Goodman, L. Fermi 1 sodium residue clean-up. Decommissioning of Fast Reactors After Sodium Draining. IAEA-TECDOC-1633, International Atomic Energy Agency, Vienna, Austria, November 2009, p. 39-44.

Gunn, J.B., Mason, L., Husband, W., MacDonald, A.J., Smith, M.R. Development and application of water vapor nitrogen (WVN) for sodium residues removal at the prototype fast reactor, Dounreay. IAEA-TECDOC-1633, International Atomic Energy Agency, Vienna, Austria, November 2009, p. 123-134.

Koch, L.J. (2008). EBR-II, Experimental Breeder Reactor-II: An Integrated Experimental Fast Reactor Nuclear Power Station, American Nuclear Society, La Grange Park, Illinois, USA, ISBN: 0-89448-042-1.

Sherman, S.R., Henslee, S.P., Rosenberg, K.E., Knight, C.J., Belcher, K.J., Preuss, D.E., Cho, D.H., \& Grandy, C. Unique Process for Deactivation of Residual Sodium in LMFBR Systems. Proceedings of Spectrum 2002, American Nuclear Society, Reno, Nevada, U.S.A., August 4-8, 2002.

Sherman, S.R. \& Henslee, S.P. (2005). In-situ Method for Treating Residual Sodium. U.S. Patent 6,919,061.

Solid Waste Disposal Act, Subtitle C, Title 42 U.S. Code Parts 6901-6992k, 2002 edition. 